\title{
MODEL TO REHABILITATE ONE VILLAGE FOR RURAL TOURISM IN QUENA GOVERNORATE
}

(Received: 4.12.2016)

\author{
By \\ H. M. Farag and M. S. A. El-Sabbagh* \\ Agriculture Extension and Rural Development Research Institute, Agriculture Research \\ Center,Giza, Egypt \\ * Human Development\&Economics Department Faculty of Fish Resources, \\ Suez canalUniversity
}

\begin{abstract}
Rural tourism is considered a successful way to increase economic and standard of living due to its contribution in creating jobs for the youth. So the present study aimed to identify a village with prerequisits to be established as tourism attraction in Quena Governorate. Moreaver to determine the constraints which could face that, in addition to propose a model for optimising the benefit from this to the inhabitants in this village. Data were collected through Oktober 2015 by using the participatory Rapid Appraisal (PRA) tool (i.e.,focus group discussion), SWOT ANALYSIS, and questionnaire. The study was carried out in three villages: Dandara, El-mahrossa, and Hager Danfek. Upon that Dndara was chosen according to the advice of the responsible people of the Governorate for its numerous tourism prerequisits. The study revealed that the constraints which could face the rural tourism in Dandara village were absence of environmental hotels or suitable places for tourists livining and not enough services for marketing. So, a porposed model of environmental hotel on a farm house - style was suggested to be established by the contribution of the village farmers taking in consideration the old rural house, and also proposed an illustration for the tourist visits to the village starting from the river nile to the Dandara musium, for enjoying with banana farms and indentifying its land preparation, planting, and harvesting by their participation in the rural life including feeding, clothing plus enjoying the village life and to move to the near village with its rural life prerequisits.
\end{abstract}

Key words: rehabilitate, rural tourism, Quena .

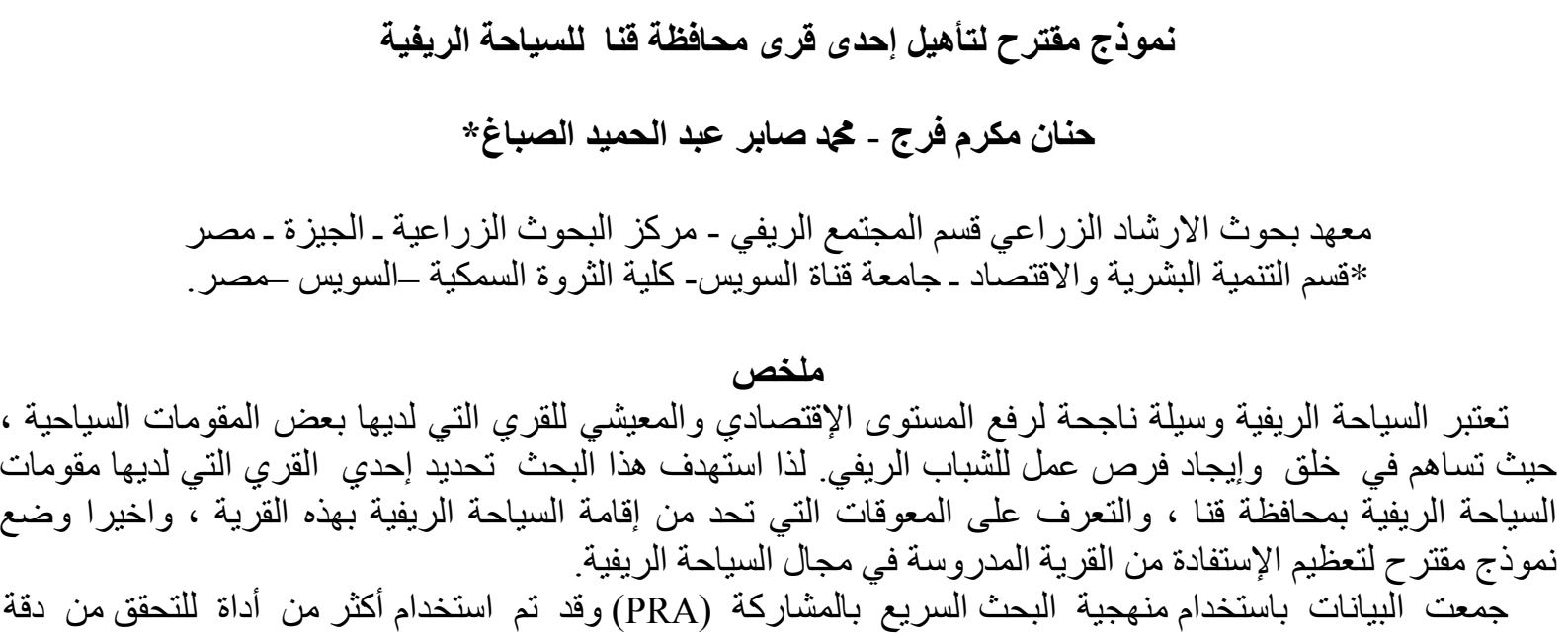


البيانات، حيث تم استخدام المجمو عات النقاشية البؤرية، و التحليل رباعي الأبعاد لتحليل مواطن القوة و الضعف و والفرص

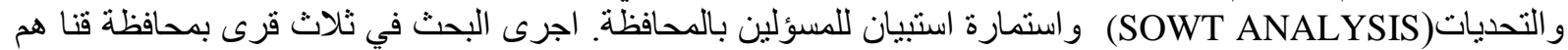

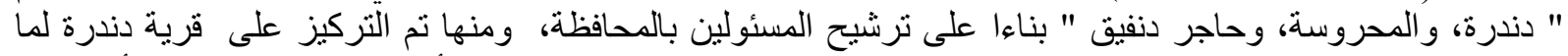

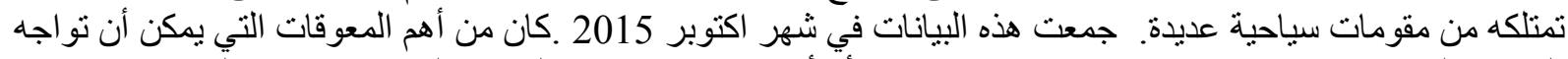

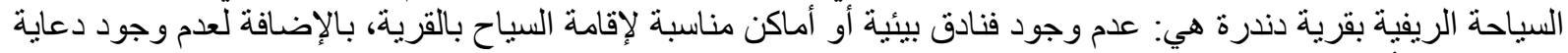

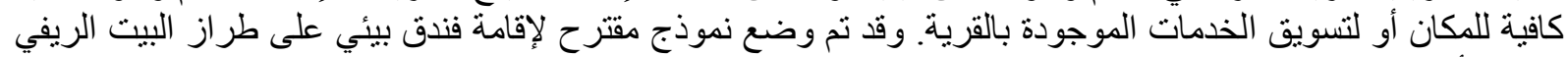

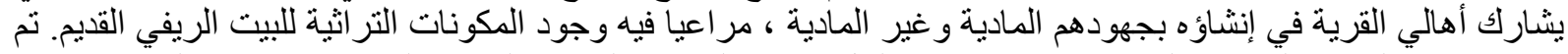

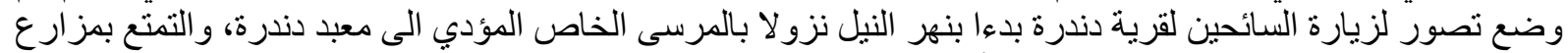

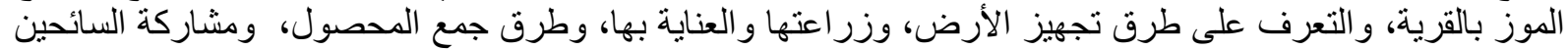

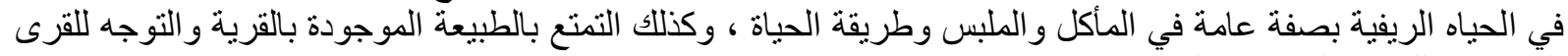

المجاورة للتمتع بالمقومات السيّاّية بها.

و إذا نظرنا إلى مفهوم السياحة الريفية فإنه مفهوم متعدد

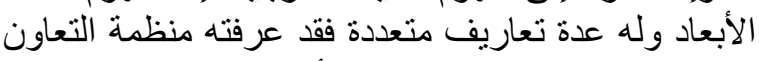

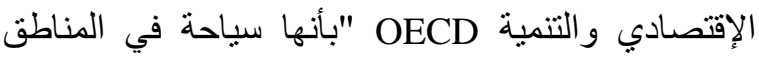

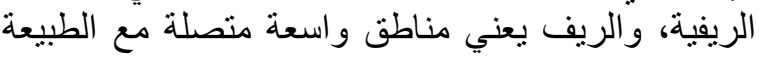

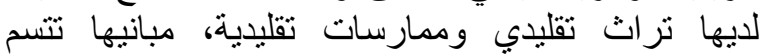
(Humaira, بالبساطة، تجمع بين" أنواع عديدة من السياحة

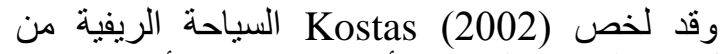
خلال هذه المفاهيم المتعددة بأنها سياحة يجب النيا أن تكون في الرئ

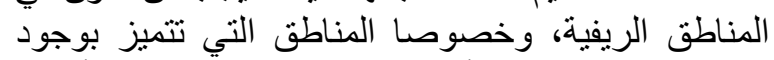

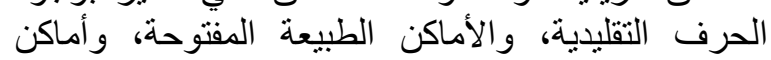

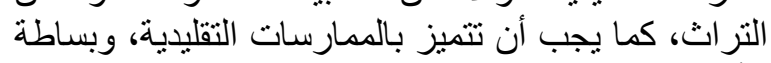

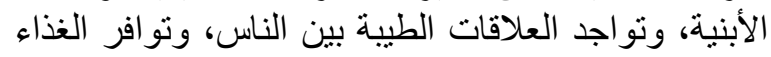

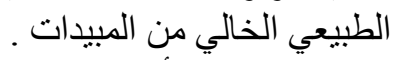

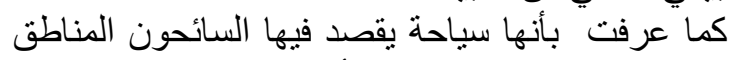

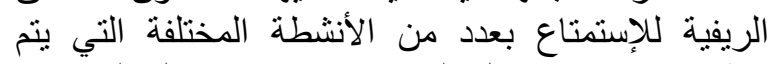

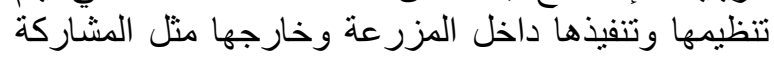

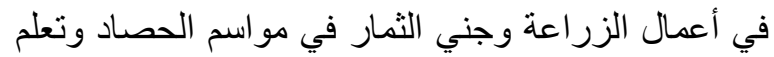

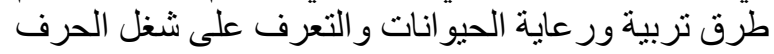

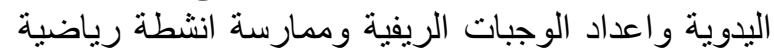

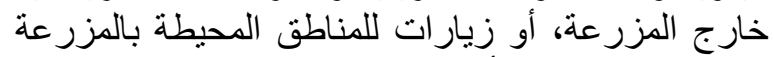

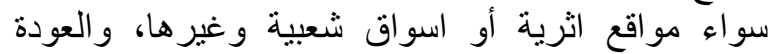

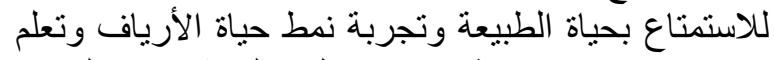

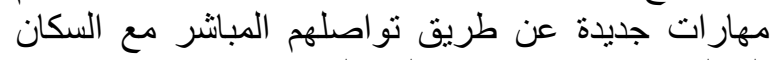

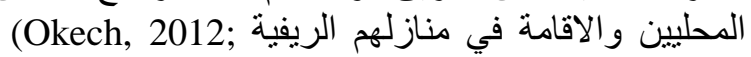
(Tugba and Özdemir 2012); (Pakurar and olah, 2008) من هذا يتضح أن السياحة الريفية تجمع في طياتها العديد

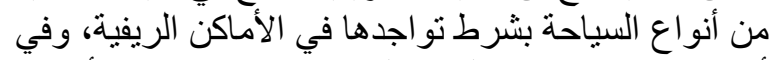

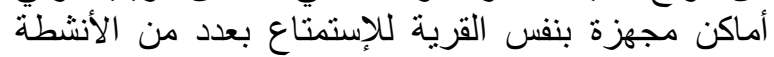

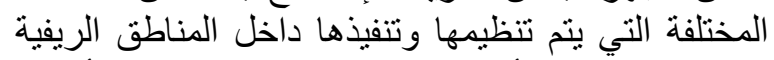

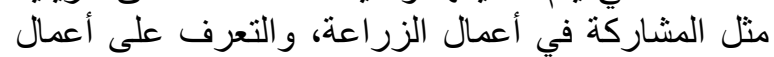

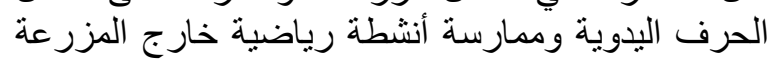

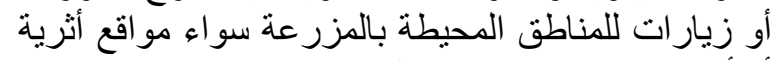

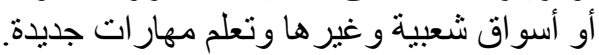

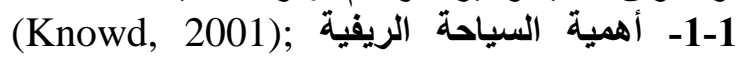

(Humaira, 2010)

\section{1. مقدمة البحث والإستعر اض المرجعي}

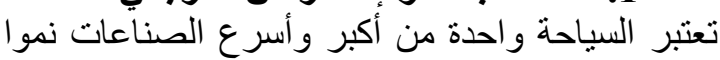

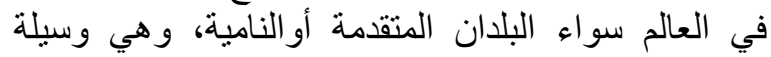

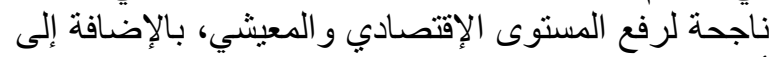

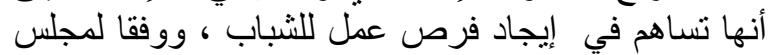

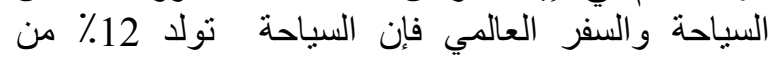

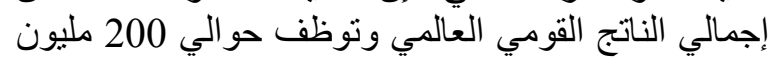

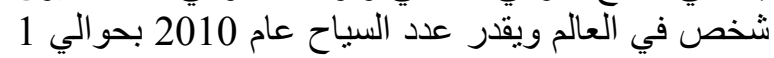

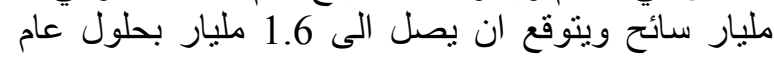

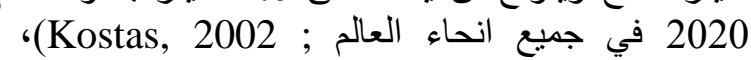

(Humaira, 2010)

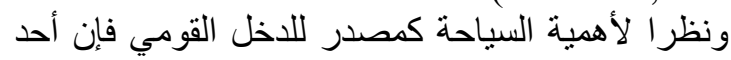

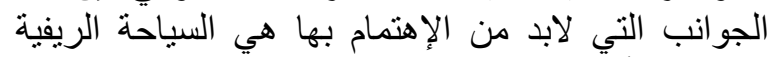

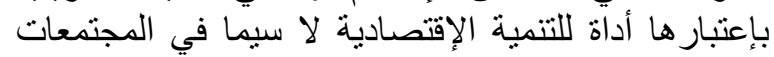

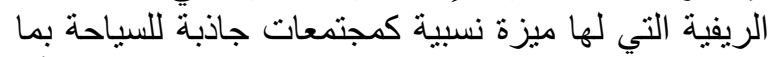

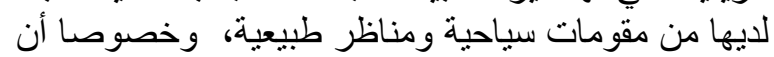

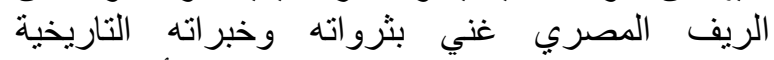

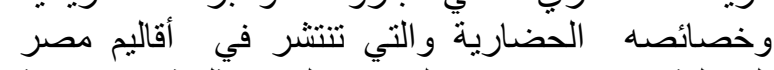

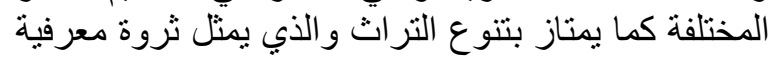
وتقنية هائلة ويمكن نوظيفها في التنميةٌ الثاملة في الريف تروة المصري.

إنتشرت السياحه الريفية في كثير من الدول النامية

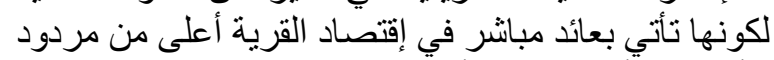

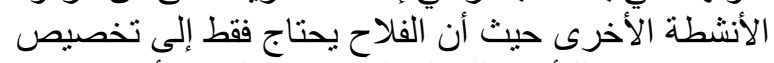

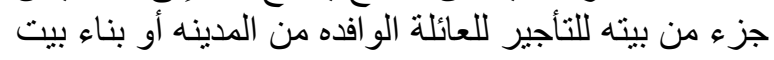

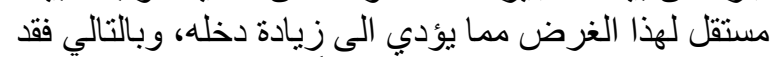

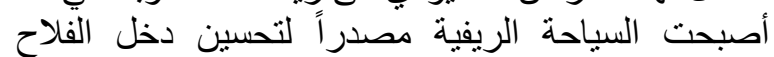
بالإضافة لكونها وسيلة لتواصلة والفئة وتفاهم أكثر بين أبناء

القرى و أبناء المدن (Knowd, 2001)

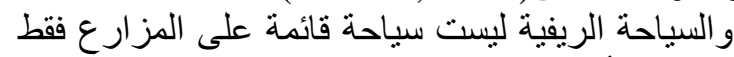

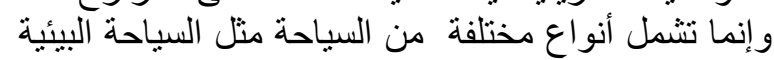

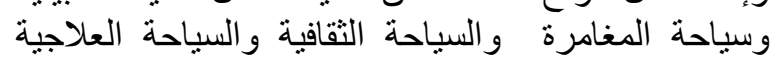

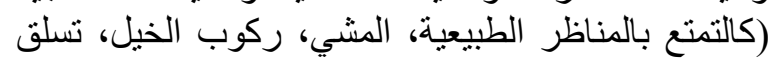

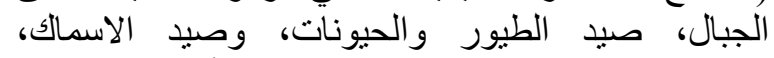
وتعليم حرف تقليدية، وفولكلور شعبي، أكلات شعبية ) . (Tugba and Özdemir,2012) 
توفر السياحة الريفية مجالا للترفيه والتعليم في التئي مجالات تتعلق بتعليمهم في العلوم الطبيعية، المهنمون

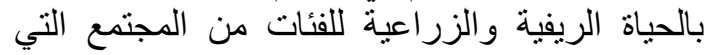

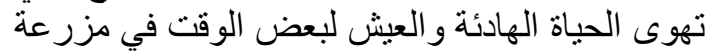

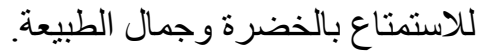

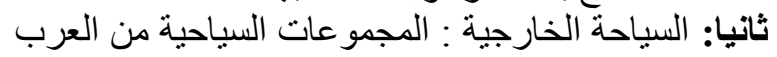

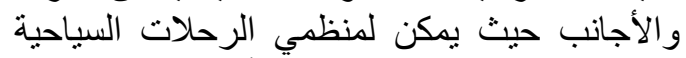

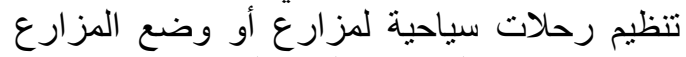

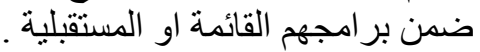
-1-1 الأهمية التطبيقية للبحث التهة

تحتل السياحة بصفة عامة، ولائة والسياحة الريفية بصفة

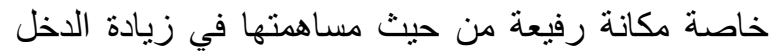

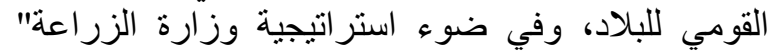

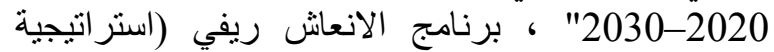

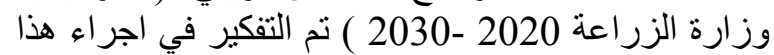

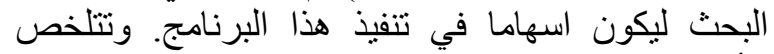

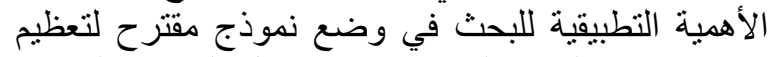

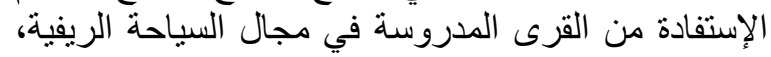

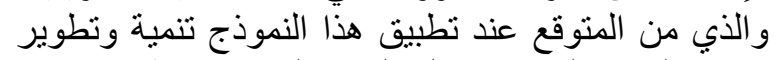

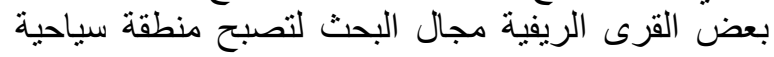

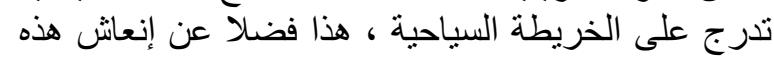

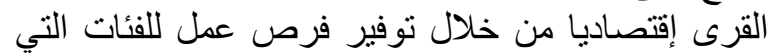

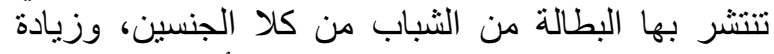
دخل الريفيين من خلال الإستخدام الأمثل للإمكانيات

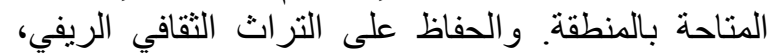

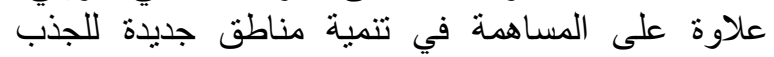

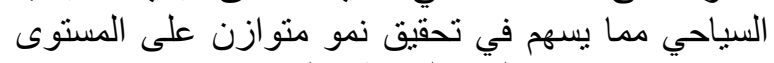

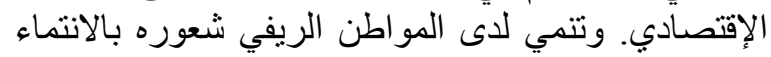

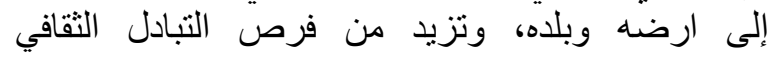
و الحضاري بين المجتمع المضيف و الزئر ائر.

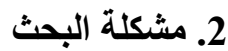

من العرض السابق يتبين أن غالبية الريفيين بعانون

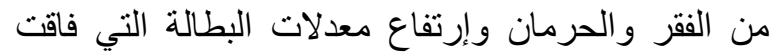

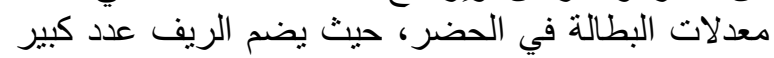

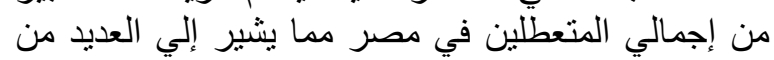

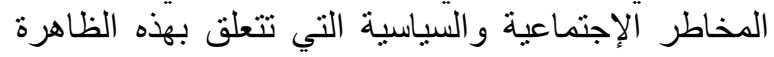

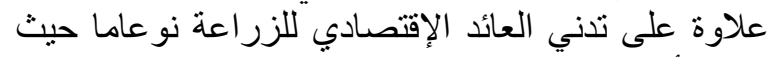

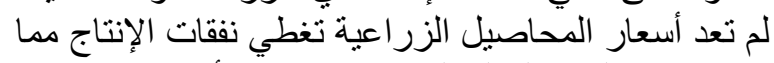

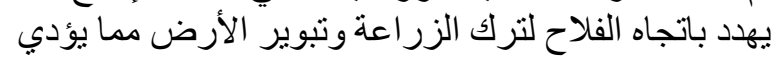
إلي زيادة العجز في توفير الغذاء. ورغم كل مأ ذكر فهناك إمكانية كبيرة لتنمية الريف ألزيف

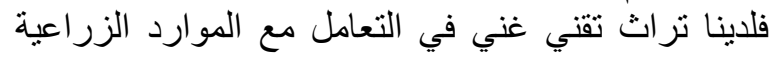

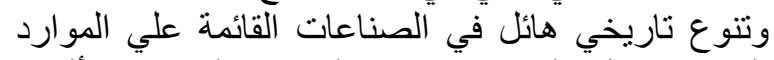

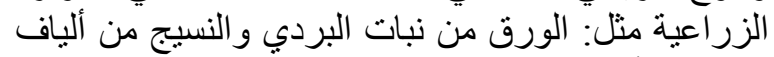

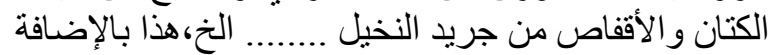

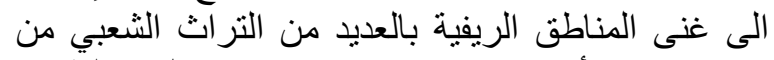

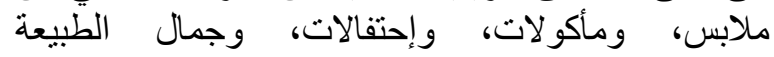

السياحة الريفية سياحة اعداد محدودة ولكنها تساهم إقتصاديا في رفع مستوى معيشة الريفية الريبين علاوة على التى أنها

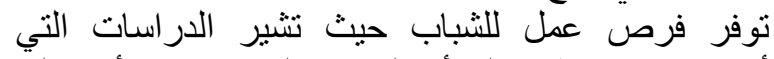

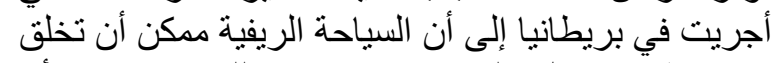

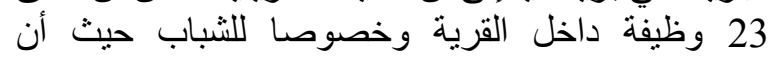
صناعة السياحة صناعة مثيرة ومناسبة لطاقات و و حماسة

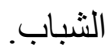

1- تساهم السياحة الريفية في بقاء المزارعين

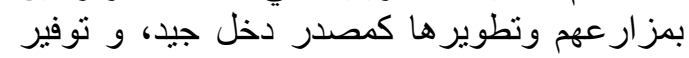

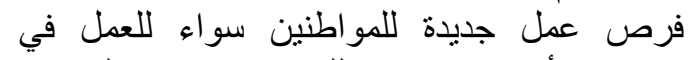

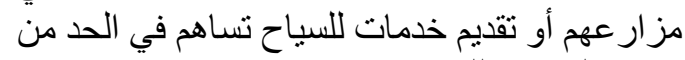

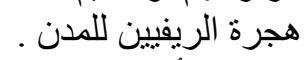

2- تدفق الأفواج السياحية يولد مجالات لاتل عمل مربحة

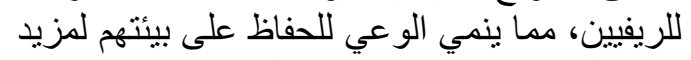

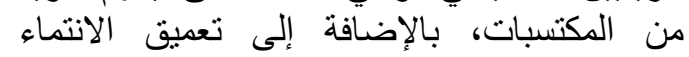
و الفخر بالإنتماء لقر اهم . 3- الحفاظ على التقافة و التراث اثل الريفي. 4- التبادل الاجتماعي و الثقافي .

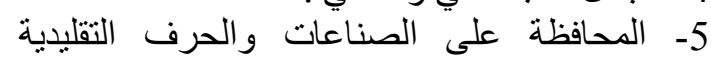

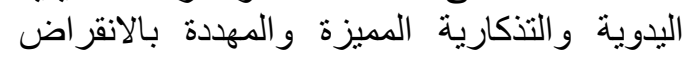

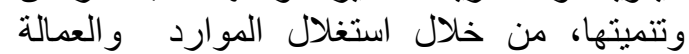

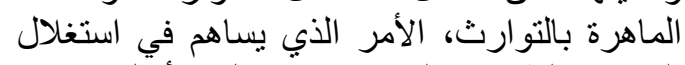

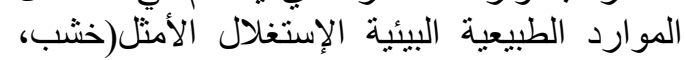
6دف ،تطريز ، جلديات).

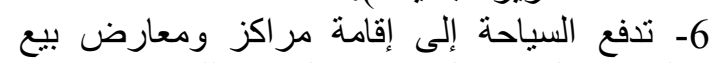

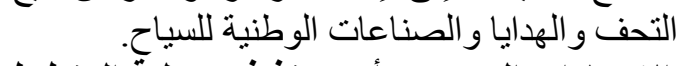

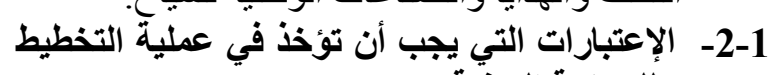
للسياحة الريفية

1- عوامل و عناصر جذبة المنب الزوار تتضمن: العناصر

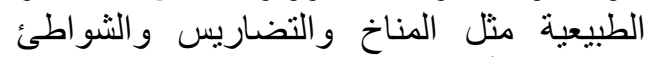

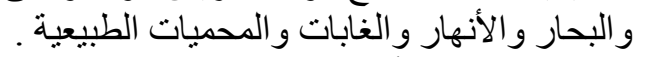
2- الدوافع البشرية : أي رغبة الريفار اليفين في استضافة الطبية السباح . السان.

3- المواقع التاريخية والحضارية و الأثرية والدينية ومدن الملاهي والألعاب .

4- مر افق وخدمات الإيواء الأعاب و الضيافة: مثل الفنادق

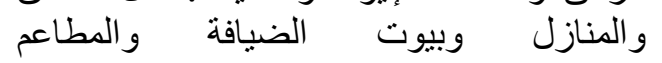
و والاستر احات.

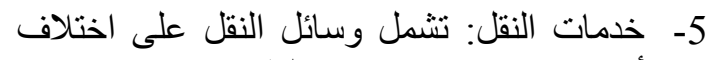

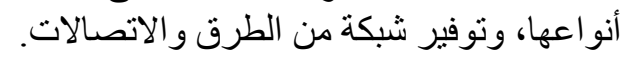

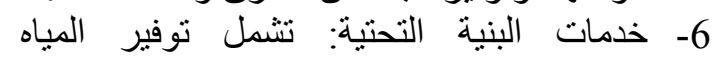

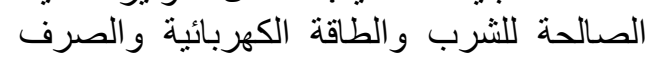
3-1 الفئات المستئهذفة تستهدف السياحة الريفية فئتين من السائحين : اولا: السياحة الداخلية وتشمل :سكان المدنة المنين الكبيرة حيث

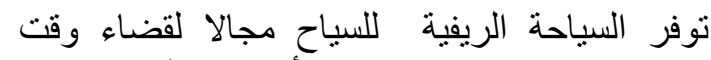

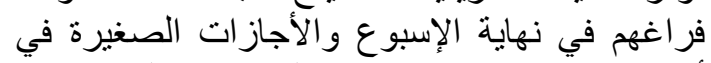
أنشطة ممتعة ومفيدة، طلاب المدارس والإس والجامعات : 
مسئول من المركز الثقافي، مسئول الوحدة المحلية، مسئول

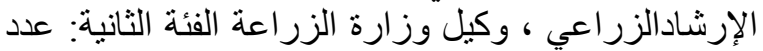

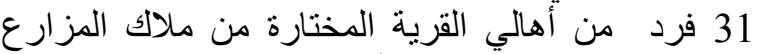

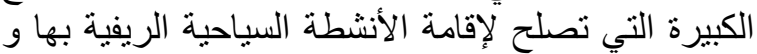

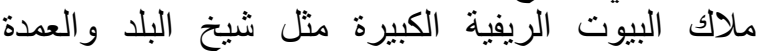

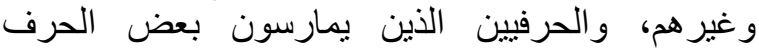
التقليدية بالقرية ، و العاملين في مجال الفونين لفين الكلور الثعبي،

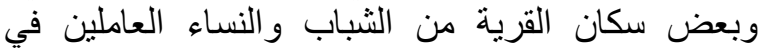
مجالات تتعلق بالسياحة معتمدين في ذللك على الإخباريين. -3-4-أدوات جمع البيانات

إستخدم في ضوء أدوان أهداف البحث منهج البحث السريع بالمشاركة وقد تم استخدام اكثر من أداه للتحقق النق من دقة البيانات المتحصل عليها حيث استخدمت إستمارة البتارة إستبيان بالمقابلة الثخصية مع خمسة من المئنة المسئولين بالمحافظة والمهتمين بمجال السياحة، وتم استخدام التحليل

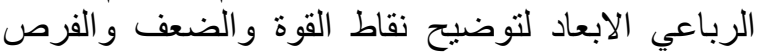
و التهديدات ، وقد اشتملت إستمارة الاستبيان مع خمسة من

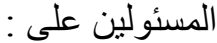

أولا: مقومات السياحة الريفية بالمحافظة من أصول عامة،هوبشرية، و إجتماعية، وطبيعية، ولية ومادية. ثانيا: معوقات قيام السياحة الريفية. ثالثا: مقترحات قيام السياحة الريفية.

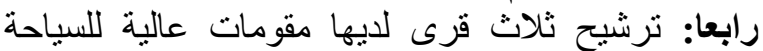

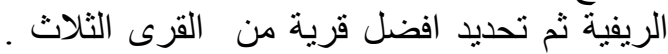

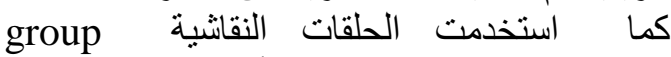

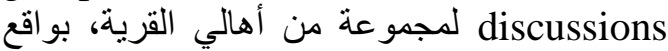

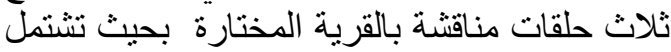
كل حلقة على (8 -12 مبحوثا)، بإستخدام دليل

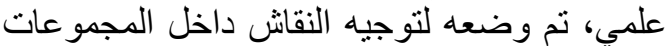

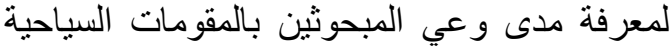
لقريتهم، ومدى إستجابتهم لإستقبال السياح بالقرية،

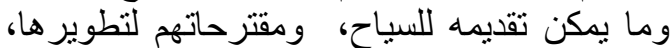
ومعوقات قيام السياحة الريفية بالقرية.

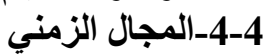
تم جمع البيانات خلاّل شهر أكتوبر 2015 4-4-4 التعريف الإجرائي للسياحة الريفية التئية

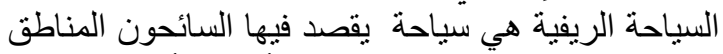

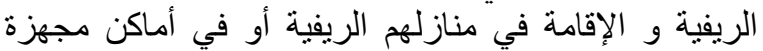
بنفس القرية للإستمتاع بعدد من الأنشطة المختلفة المالفة التي يتم

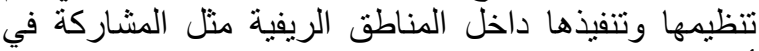

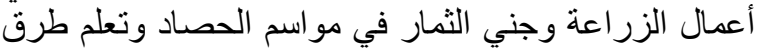

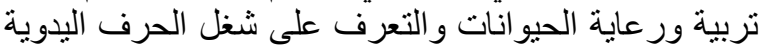

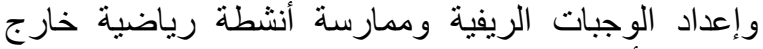

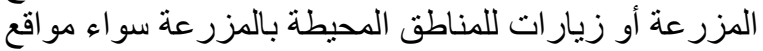

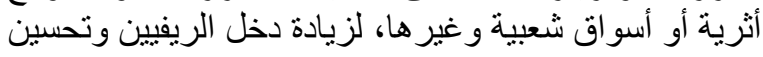

مستوى معيشتهم

\section{5- 5تائج البحث}

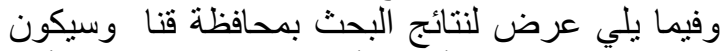
هذا العرض من خلال أربعة أجزاء: يختص الجزء بلألأول
و المحميات الطبيعية، و الجبال، و الأنهار مما يعطينا ميز ات بات بئات

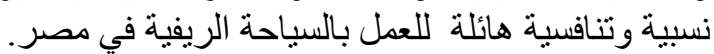

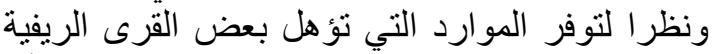

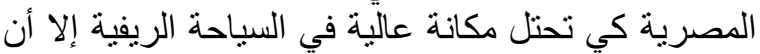

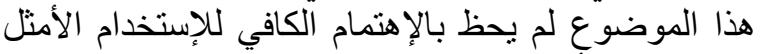

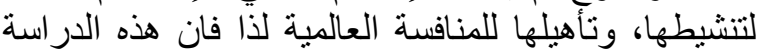

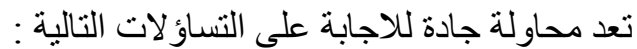
ماهي أكثر القرى التي لديها مقومات للاتسياحة الريفية

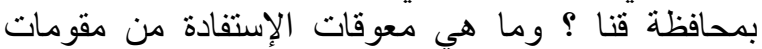

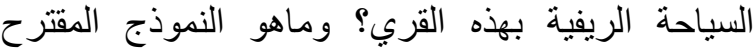
لتأهيلها للسياحة الريفية . ل الريفة

\section{3. أهداف البحث}

مما سبق عرضه بمشكلة الدراسة يمكن تحديد الأهداف

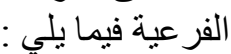

1- تحديد قرية لديها مقومات للسياحة الريفية في منطقة

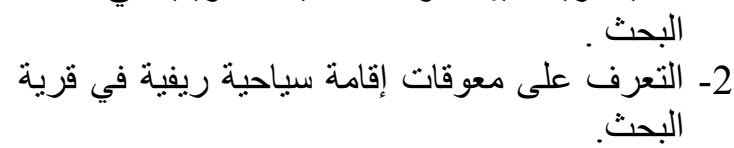
3- وضع نموذج مقترح لتعظيم الإستفادة من القرية المختارة في مجال السياحة الريفية .

\section{4. - الطريقة البحثية}

تم استخدام منهجية البحث السريع بالمشاركة (RAP)

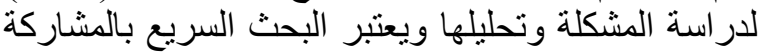

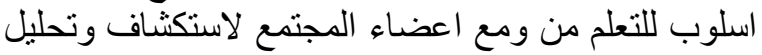

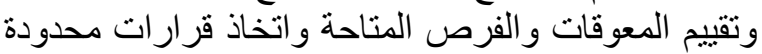
تجاه المشروعات التنموية ـ و هو بمثابة وسيلة يمكن من الثنات

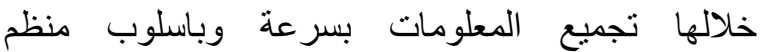

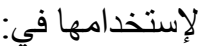
إجراء تحليل عام لموضوع أو مشكلة معينة، تقدير

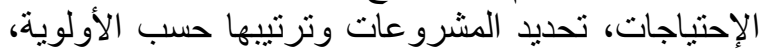

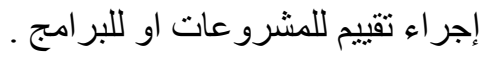

تم إختبار محافظة قنا كأحد محافظات الجمهورية

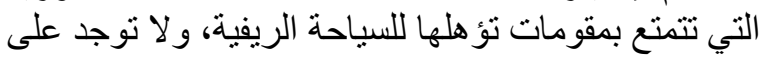

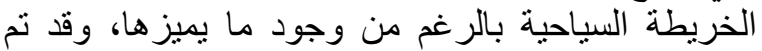

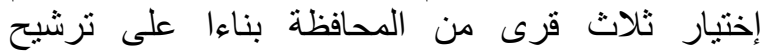

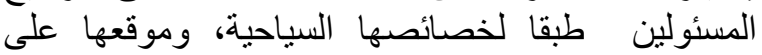

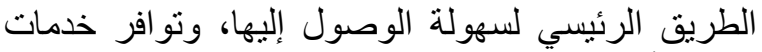

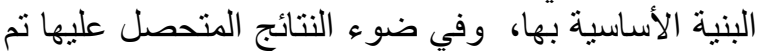

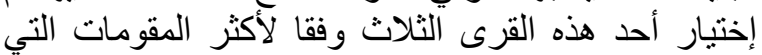

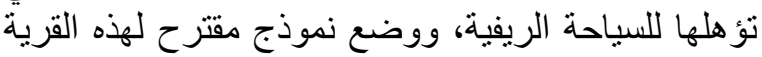
لتكون قرية سباحية نموذجية.

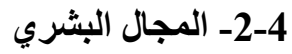
ينقسم المجال البشري لفئتين هما:

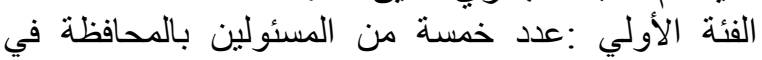
مجالات ذات العلاقة بالسياحة : مسئول بوز ارة السئن السياحة، 
3- تتميز بوجود بعض القوى البشرية الخبيرة في مجالات الحرف البيئية التقليدية مثل التئل الخزف،

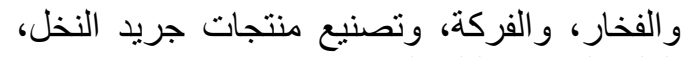
الكليم اليدوي، البلح المجفة ولفئ

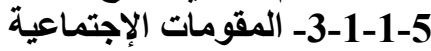

1- تثميز بوجود المأكولات الثتعبية الخاصة بأهل

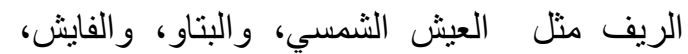

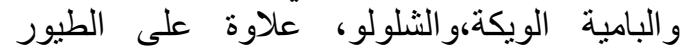

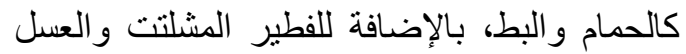

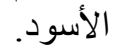

2- وجود بعض الفرق الغنائية والفنون الثعبية الغناء على الربابة، ورياضة التحطيب.

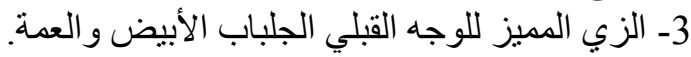

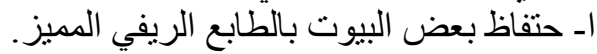

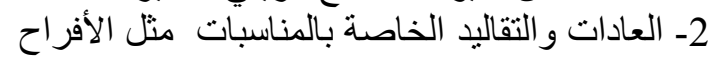

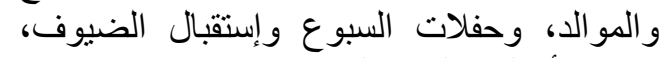

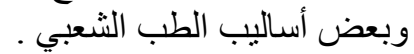

4-1-1-5 المقومات الطبيعية

1- 1- تتمتع محافظة فنا بالتنوع الطيعة النيعي حيث يمر

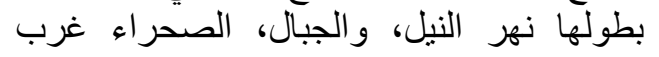

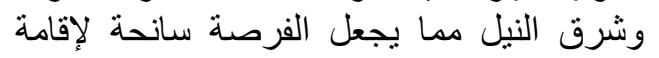

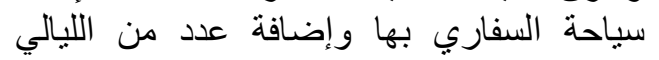

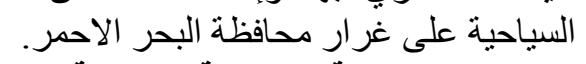

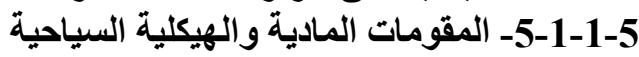

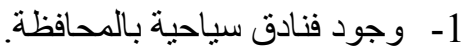

2-

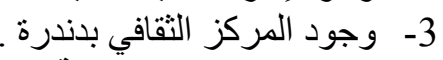

ك-1-1-5- وجود مقومات سيّاحية بالمحافظات المجاورة

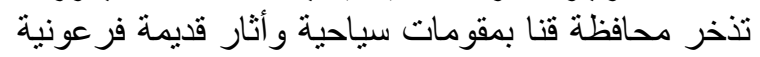

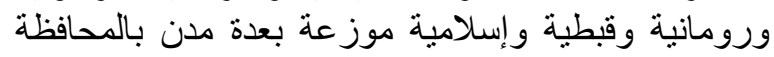

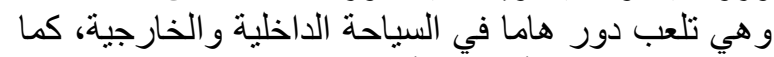

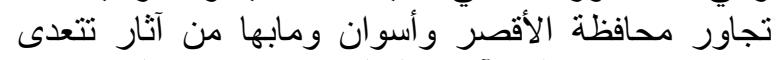

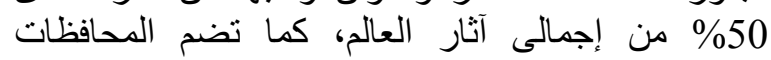

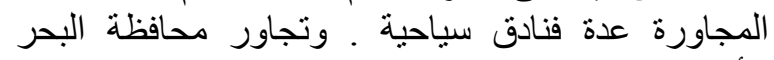

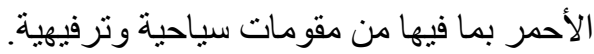

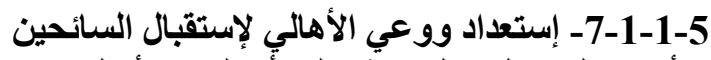

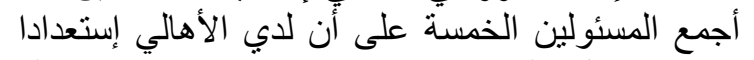

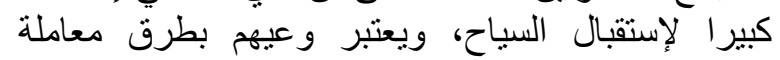

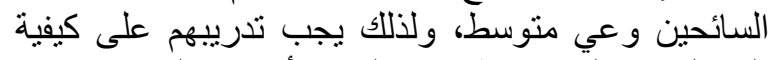

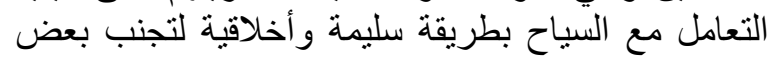
المشاكل الني تعطي السائح إنطباعا سيئا عن السية لنياحة بعضة

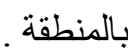
8-1-1-5-إمكانيات يمكن إستخدامها و تطوير ها للسياحة الريفية مستقبّلا يمكن إنتخ

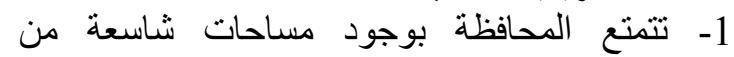
الصحر اء غرب وشرق القغة النيل مما يجعل الفرصة

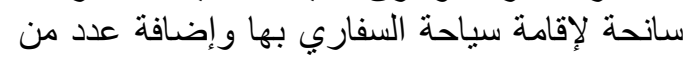
الليالي السياحية على غرار محافية اليفة البحر الاحمر
بعرض نتائج البحث الخاصة بالمقابلة الثخصية للمسئولين

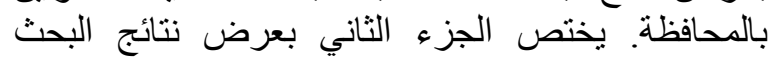
الخاصة بالحلقات النقاتثية التي إجريت بالجئ بالقرية المختارة.

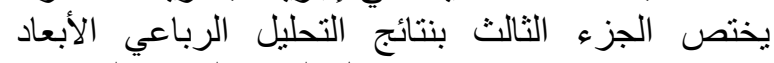

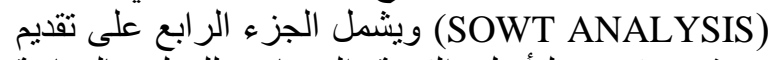

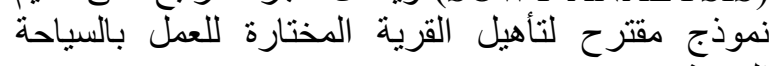

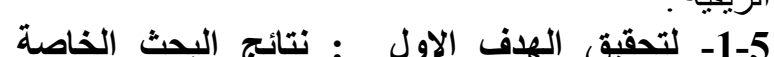
بالمقابلة الشخصية للمسئولين بالمحافظة البهان

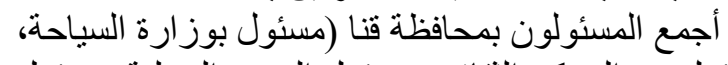

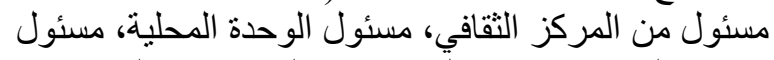

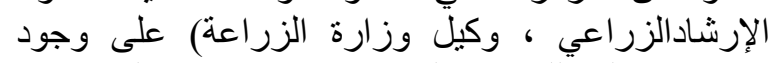
مقومات عالية للسياحة الريفية بمحافظة قنا والزئ التي يمكن

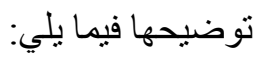
1-1-5 بعض المقومات السياحية التي تتميز بها محافظة قنا

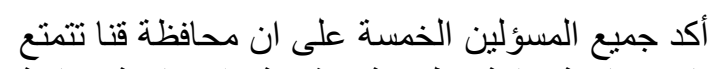

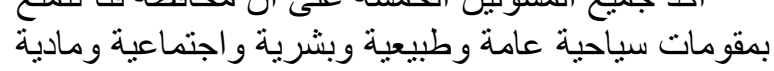
متعددة يمكن حصر ها فيما يلية عامئية 1-1-1-5

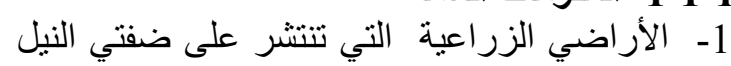

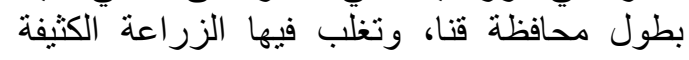

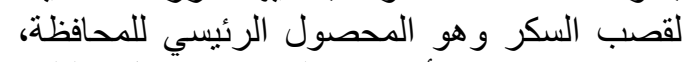

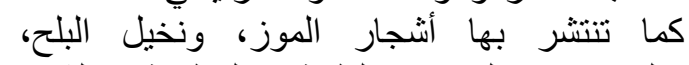

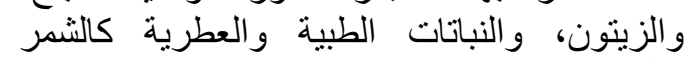

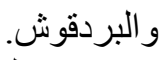

2- وجود سكك حديدية، واتوبيسات سياحية، علاوة على قربها من مطار الأقصر. 3- المعالم و الآثار القديمة ونار الافتاحف.

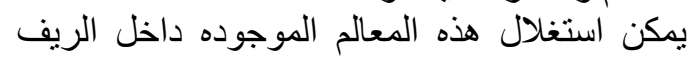

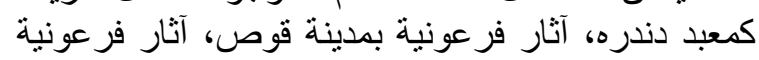

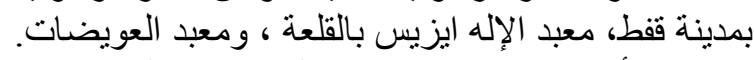

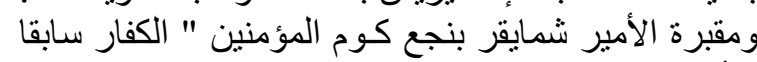

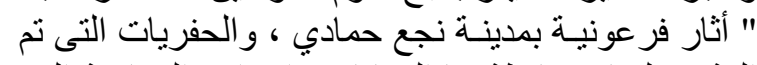

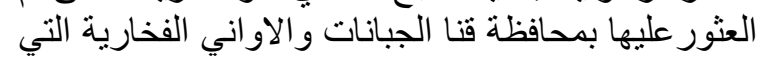

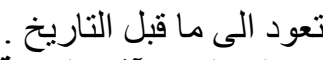
1 - المعالم والآثار الإينية:

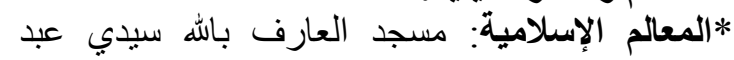

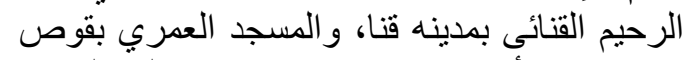

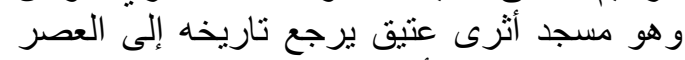

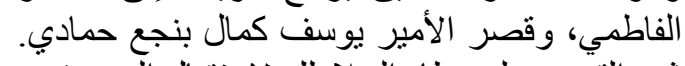

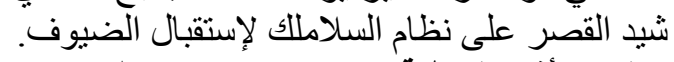

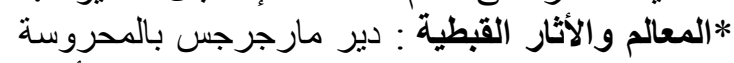

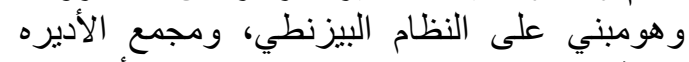
بقرية حأجر دنفيق مركز نقاده ويضم سبعلية أديره الأبره -2-1-5 1- أكثر من ثلاثة أرباع سكان البثرية المحافظة ريفيين .

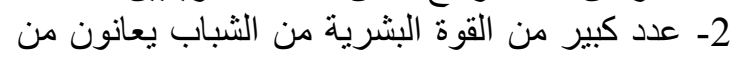

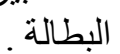


منتجاتهم، وتخصيص أماكن مناسبة لتصنيع منتجاتهم بها.

8- الإهنمام بخدمات البنية الأساسية من رصف طرق لإن وإنارة شوارع والإهتمام بالمستشفيات لإستيعاب رلاب الإن

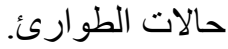

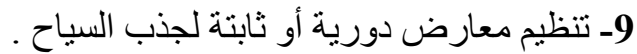

4-1-5-اختيار قرية لإقامة نموذج للسياحة الريفية الرئية

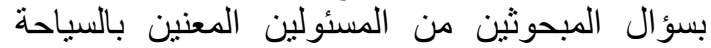

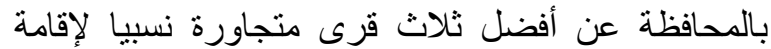

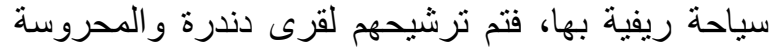

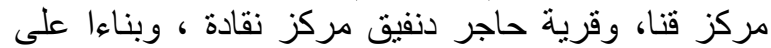
هذه الترشيحات تم زيارة القرى الثنلاث لتحديد أكثر القرى

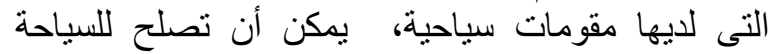

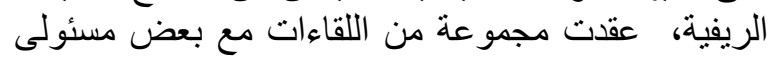

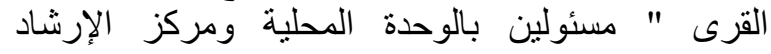

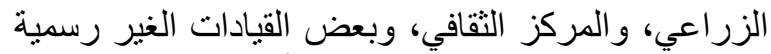

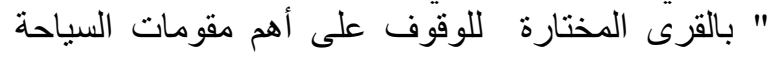
الريفية بهذه القرى، وبناءا على نتائج هذه المقات المقابلات تم

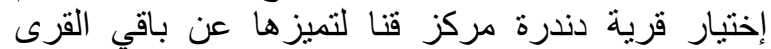

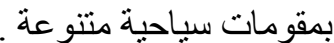
ويمكن وصف قرية دندرة كما جاء بدراسة (مركز

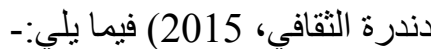

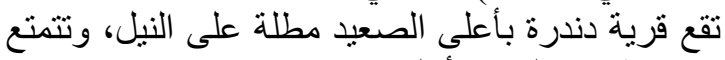

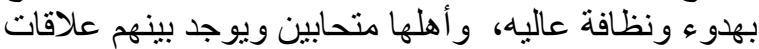

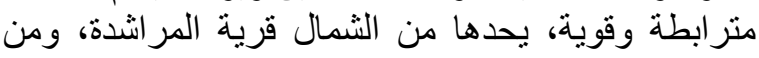

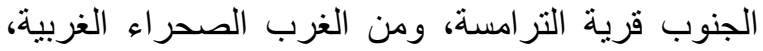

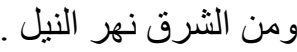

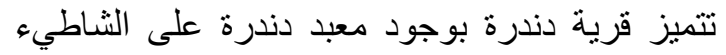

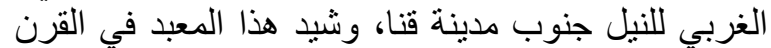

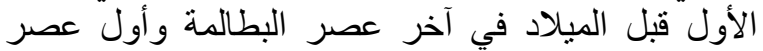

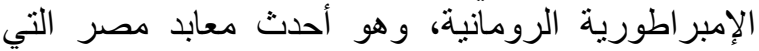
تحتفظ برونقها حتي الآن، بني هذا الآني المعبد لعبادة الإله

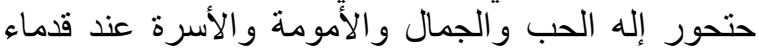

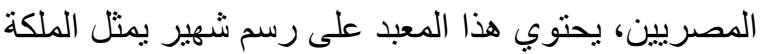

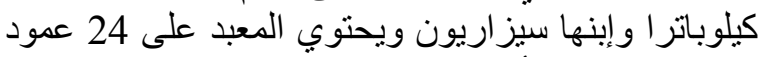

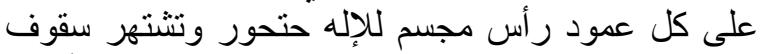
المعبد بالرسوم الفلكية العديدة التي تضم دائرة التئل الأبراج

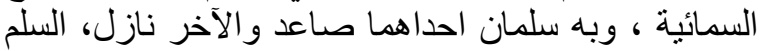
الأول به 365 درجة سلم تمثل عدد ايام السنة البسيطة

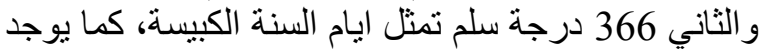

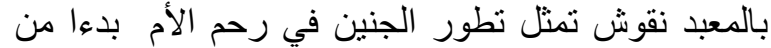

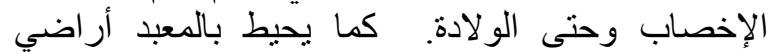
زر اعية، وبيوت ريفية، ومناظر طبيعية خلابه.

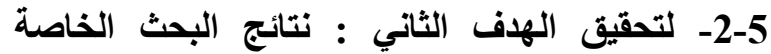

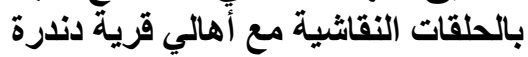

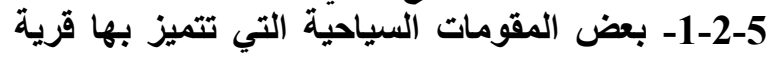
د اندرة

وبناءا على ماسبق تم عقد ثناث حلقات نقانشية بقرية دندرة الحلقة الأولى حضر ها 12 فرد من أهل القرية من
2- إمكانية عمل مهرجانات سياحية على كورنيش النيل

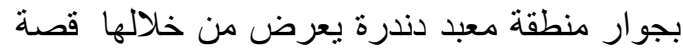
إيزيس وأوزوريس كاملة بطريقة أوبر الير العايدة .

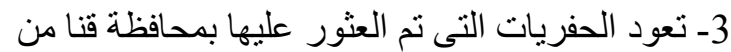

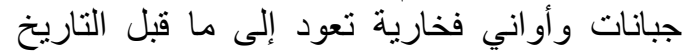

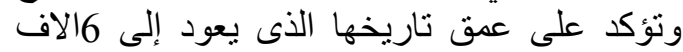

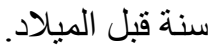

4- تسليم وزارة الثقافة 5 أفدنة لإقامة متحف للأثار

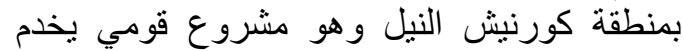
المحافظة لما يمثلك من أهمية أثرية.

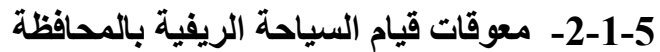

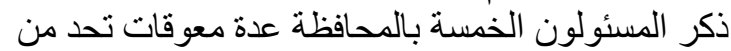

قيام السياحة الريفية منها:

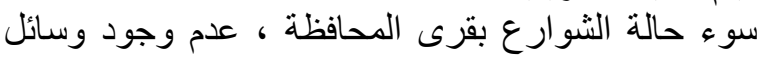

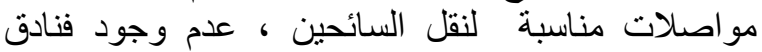

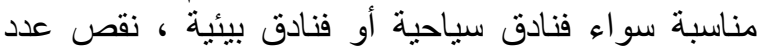

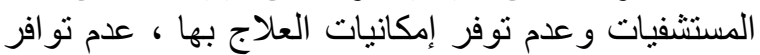

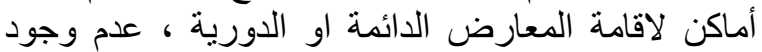

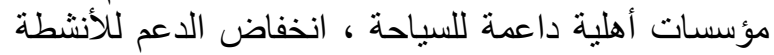

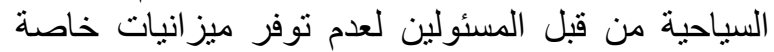

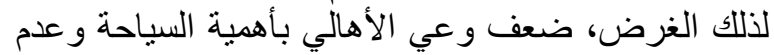

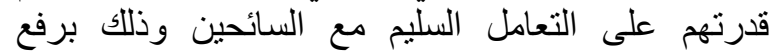

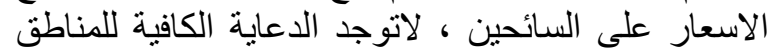

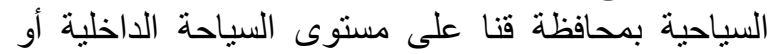
الخارجية ، صعوبة تأمين الأماكن السياحية نتيجة للإنفلات الإلية التيات

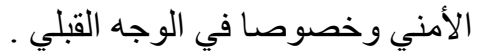

3-3-5 مقترحات المسؤلين "لقيام السياحة الريفية

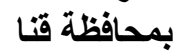

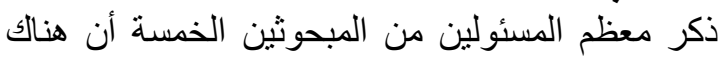
بعض المقترحات التي يجب الأخذ بها للنهوض بن بالسين النياحة

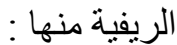

1- تحقيق ورفع كفاءة الأمن لطمئنة السائحين على الألى

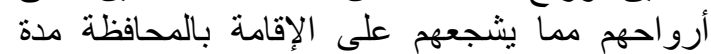

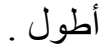

2- الإهتمام بالدعاية الكافية عن الأماكن السياحية بالمحافظة عن طريق عمل أفلام تسجيلية، ومنشور الإكن الاتية

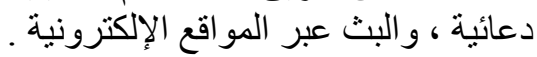

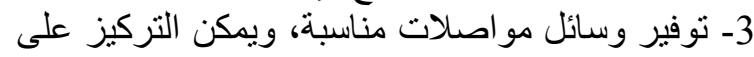

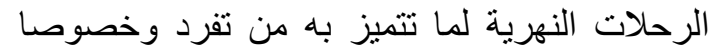

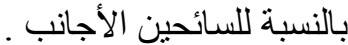

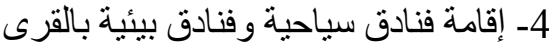
5- توعية الأهالى بأهمية السياحة الريفية لتحانية لتحسين مستوى كعيثتهم ونشر أخلاقيات التعامل مع السائح.

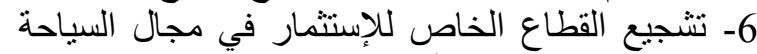

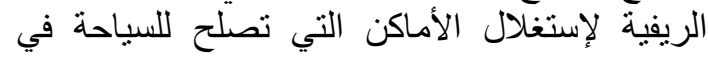

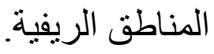
7- تقديم الدعم الفني و المالي للعاملين بالحرف التقليدية، وتدرييهر على تطويرهاً و إقامة المعارض بلفين لتسوفيق 
إلى القاهرة عندما يأتون لقضاء الأجاز ات و العطلات

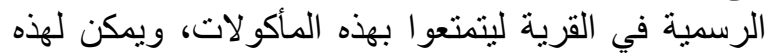
المأكو لات أن تكون مصدر الجذب لفين للسياح أيضا.

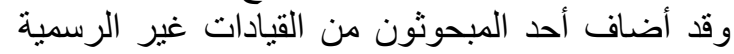

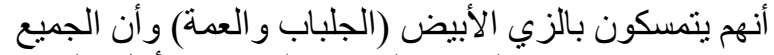

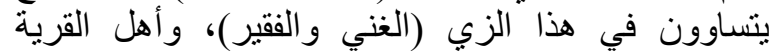

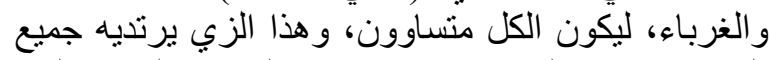
المشاركين في المنتدى الإقتصادي و المنتدى الثنافي الزئي الذي

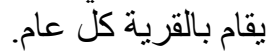
وقد أضاف معظم المبحوثون عام على أنه يقام بمركز دندرة

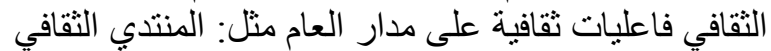

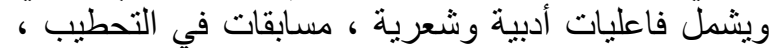

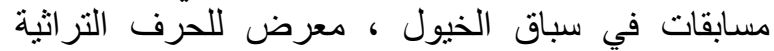
و البيئية، و المنتدى الإقتصادي ويشمل محاضر ، لإت ات في ريادة

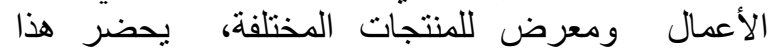
المنتديات آلاف من الز ائرين من جميع الدول العربية وضئر غير وعن الأماكن الطبيعية الجاذبة بقرية دندرة فقد أثنار كبار المزارعين وبعض الإهين الطيادات غير الرسمية بأنه يوجد

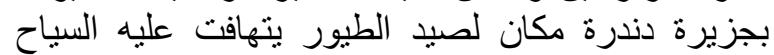
لممارسة صيد البط وسط النيل لنيل، كما إنه يمكن الإستفادة بالجبال التي تحبط بالقرية لعمل رحلات سفاري.

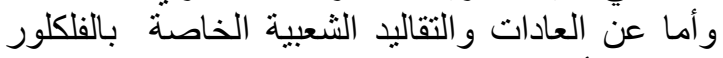

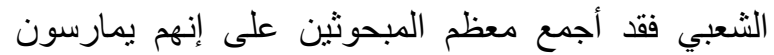

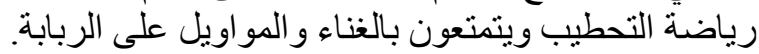

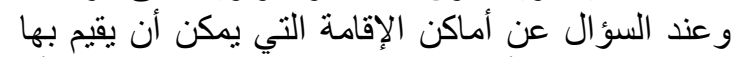

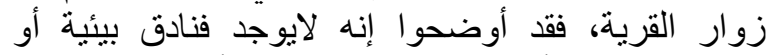

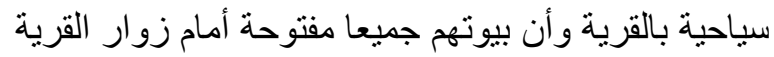

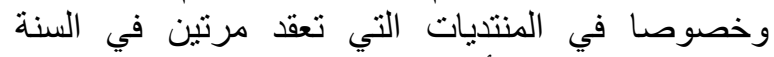
بالقرية، وليس لديهر أبي مانع من إقامة هذه الفيات الفنادق البيائية ومن إستضافة السياح من أبي نوعية سواء هذه السية السياحة السية

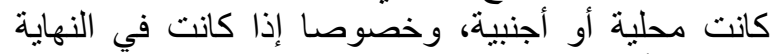

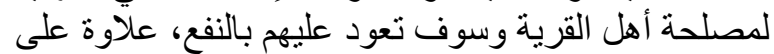

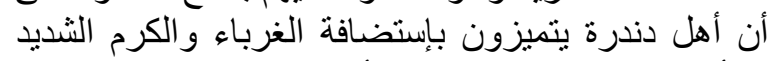

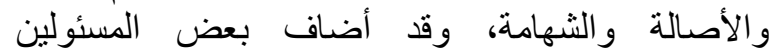

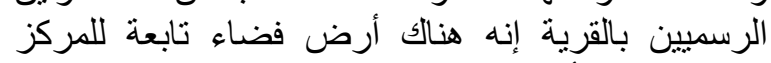
الثقافي يمكن أن يقام عليها نموذج للإنيت لليت الريفي يمكن

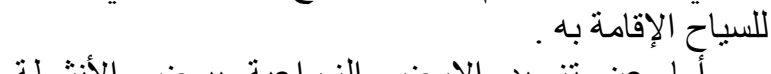

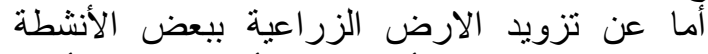

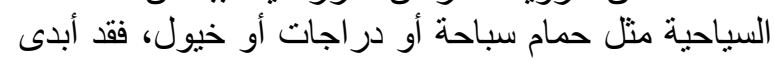

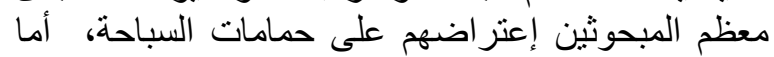

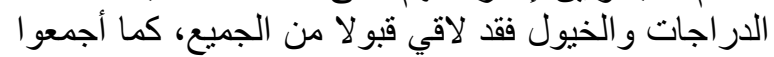

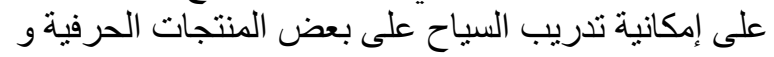
تقديم الوجبات الريفية المتميزة ، وعلئ وعل رحل رحلات سفاري

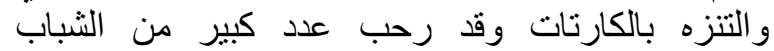

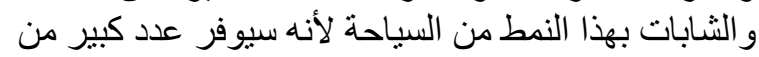
الوظائف وخصوصا للثباب النباب و المر أة الريفية.

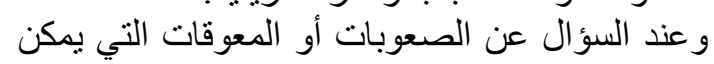
أن تو اجه السباحة الريفية بقرية دندرة فقد اتفق بعض القغات التقادة

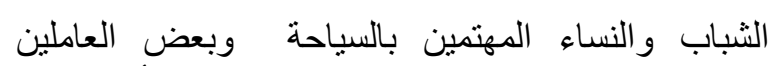

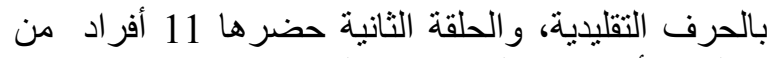

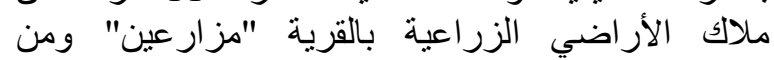

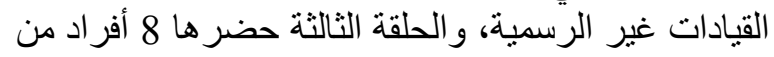

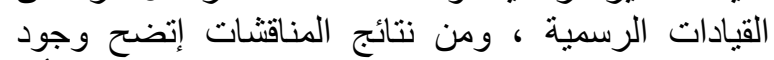

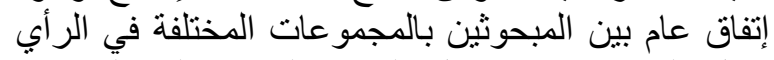

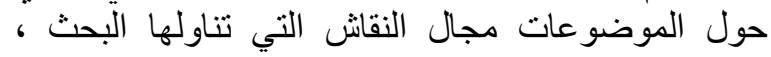

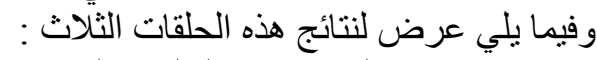
إتفق جميع الحاضرين بالحلقات النقانثية على على أن قرية

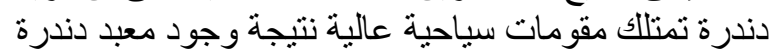

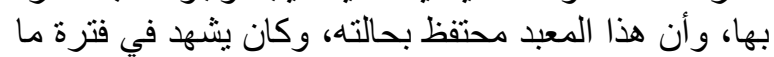

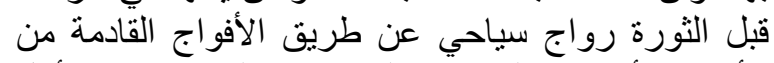

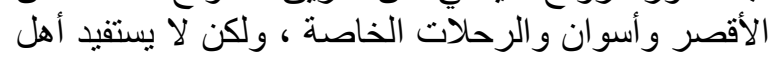

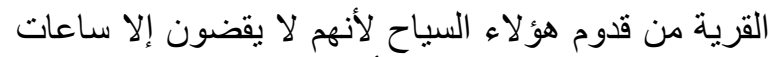

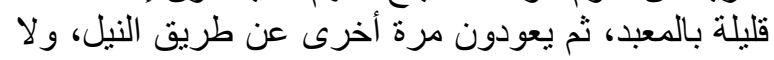

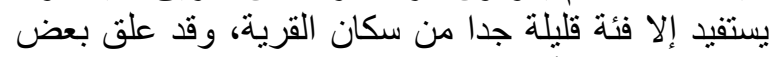

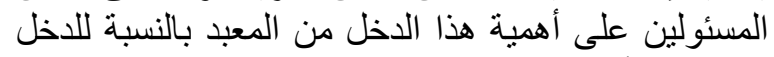

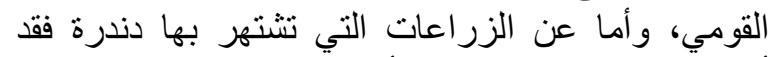

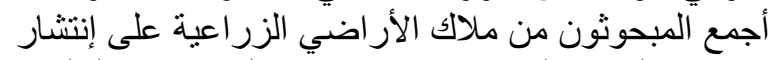

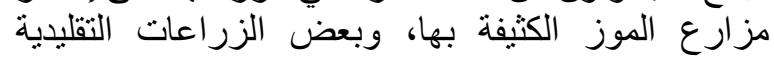

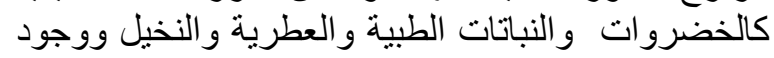

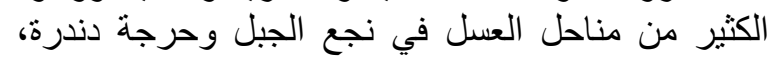
ولكن لايوجد بالقرية مهرجانات العنات زر اعية.

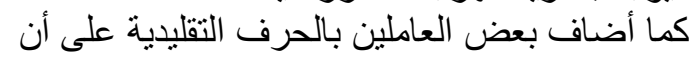

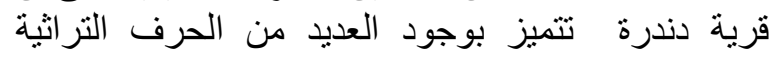

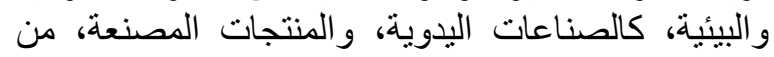
خامات طبيعية مثل صناعة صناعة الفخار التي تعمل بهات بها 200

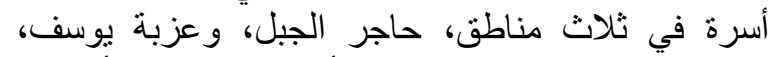

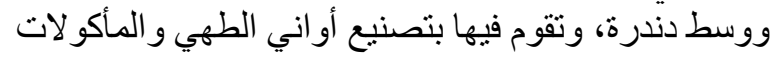

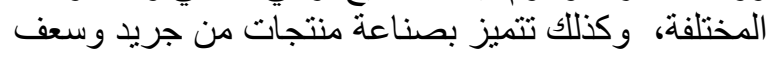

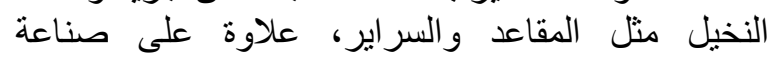

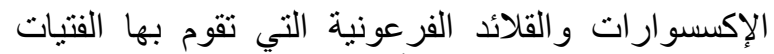

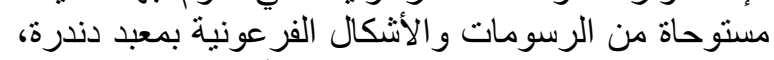

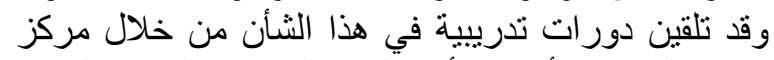

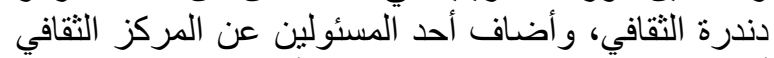

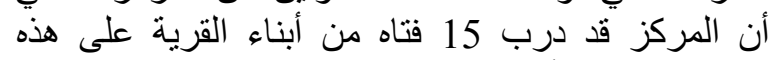

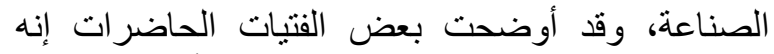

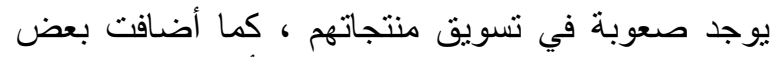

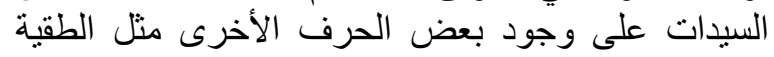

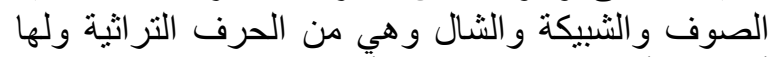

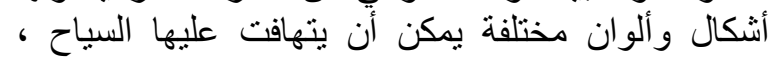

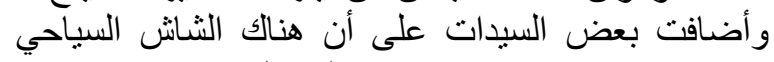

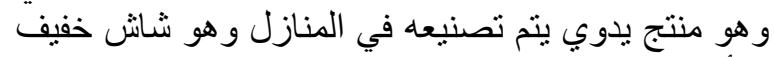
له ألو ان مختلفة.

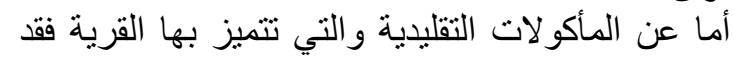

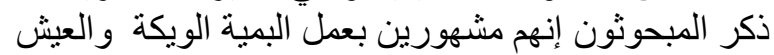

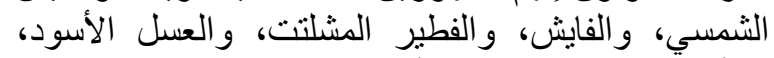

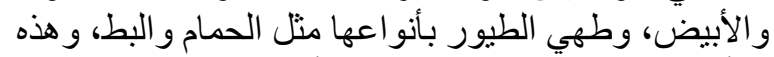
المأكو لات يعشقها سكان المدن من أبناء القرية الذين نزحوا 
عليها وعلى طريقة رعايتها وتغذيتها وحلبها

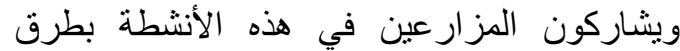

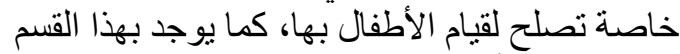

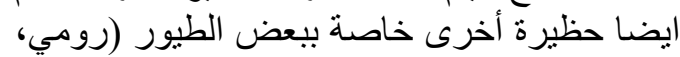
دجاج، بط، أوز) يقوم فيها الأطفال بمر اقبة سلوكئك (لئك

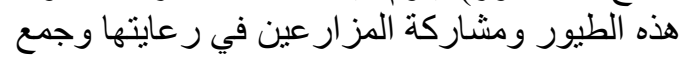

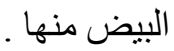
2- القسم الثاني (ركن الألعاب )

خاص بممارسة بعض الألعن الأباب التراثية الريفية بشكل

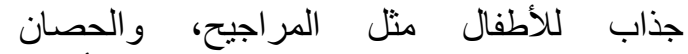
الخشبى........الخ ـ كما يمكن تجهيز بعض الئل الألعاب

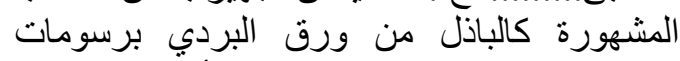

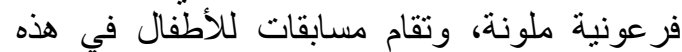
الألعاب ويأخذ الأطفال هذه الألعاب كهابـ لإنفا تذكارية مصرية لهم .

3- القسم الثالث (الورشة القنية ) ويتم فيها ـ ممارسة الأعمال الفنية حيث يمارس فئه فئها الأطفال

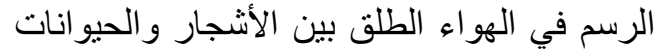

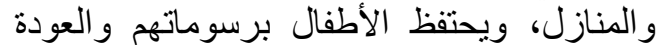

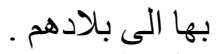
ـ ـ عمل المجسمات لنماذج من حيوانات المزرعة و المنازل من الفخار.

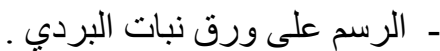

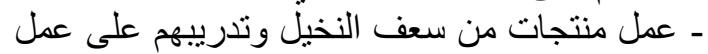

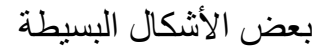

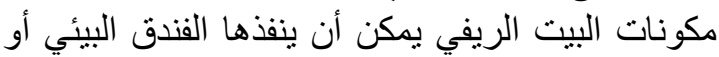
بعض المنازل الريفيةالواسعة أو التي يحبط بها بها مساحات التهات

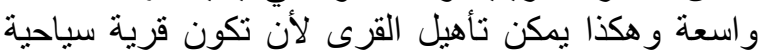

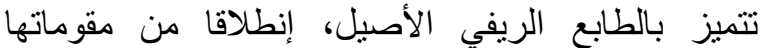
وطبيعتها الساحرة، والتي تحوي التئي بداخلها أنثار ومناظر

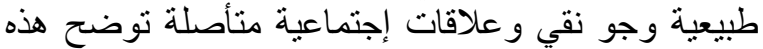
الرؤية مدى إمكانية الإستفادة من مقومات القيات القرى الريفية

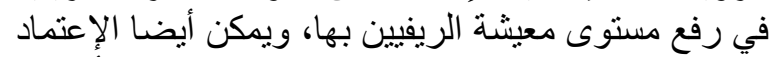

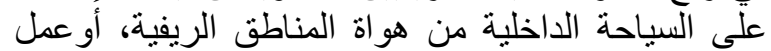

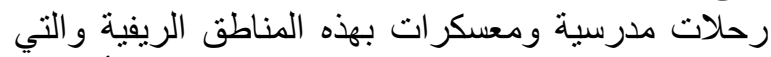

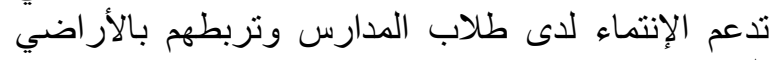
2-3-5 - ويمكن وضع تصور لزيارة السائحين لقرية

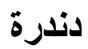

1- تبدأ الرحلة بنهر النيل نزو لا بالمرسى المؤدي الى بلى

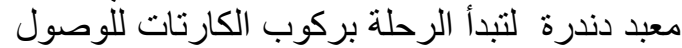

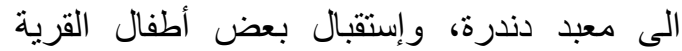

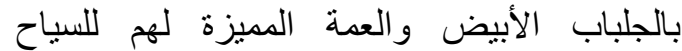
و إعطاءهم هدايا تذكارية من منتجات القرية وأخذا لأخذاح بعض الصور مع مع الأطفال . 2- زيارة لمعبد دندرة للتعرف اللفول على تاريخه .

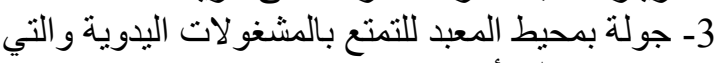

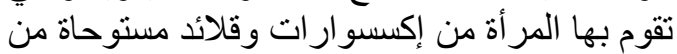
نقوشات المعبد، مع إناحة فرصة للسياح مشاركتهر

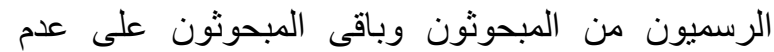
وجود فنادق بيئية او أماكن مناسبة لإقامة السياح بالئية بالقرية ،

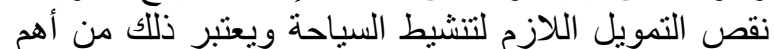

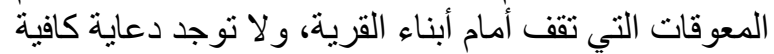

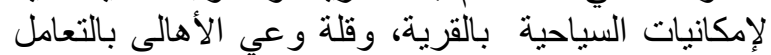

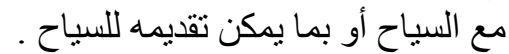

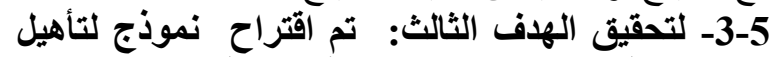
قرية دندرة للعمل بالسياحة الريفية الثراحية

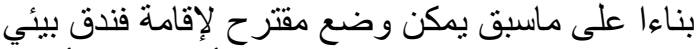

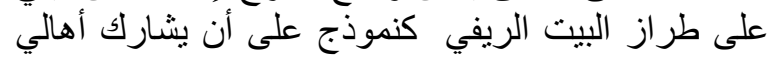

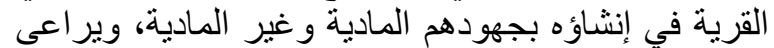
في هذا البيت وجود المكونات التراثية للبيت الريفي القديم

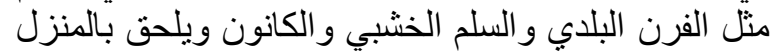

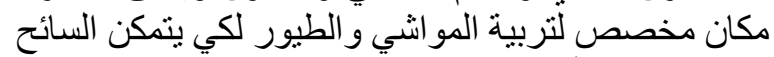

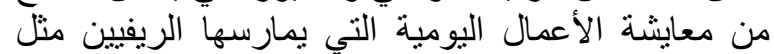
خبيز العيش و الفطائر وحلب المانشية والأدوات المئية المستخدمة

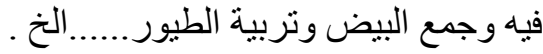

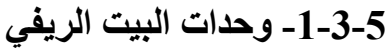

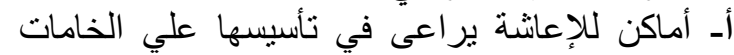

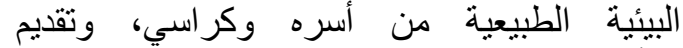

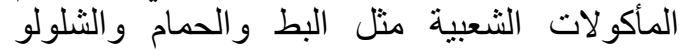

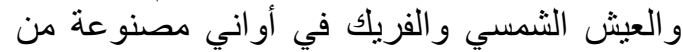
الخامات البيئية من أو اني فخارية أو المئي المصنعات من ون

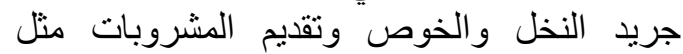

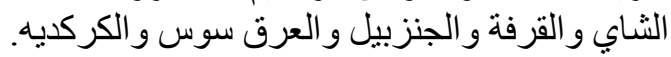

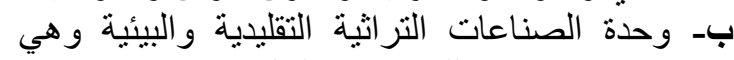
عبارة عن ورش للصناعات التقليدية منها : لئل

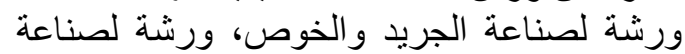

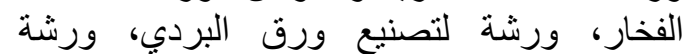

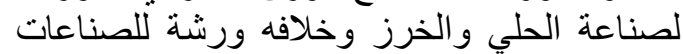
القائمة على التخلفات المزرعية كالموز، أو نخيل

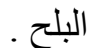

ج- وحدات الخدمات التسويقية وهو معرض دائم عبارة

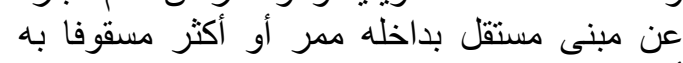

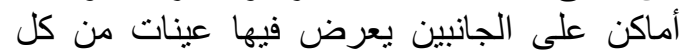

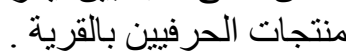
دـ أماكن مفتوحة للخدمات الترفيهية والترية الفلكلورية وتتوفر

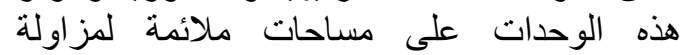
الأنشطة الثعبية والإحتفالات بالمناسبات الثاتهات الثعبية

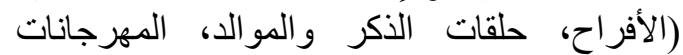

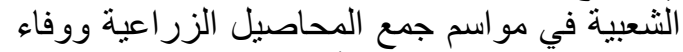

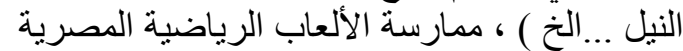

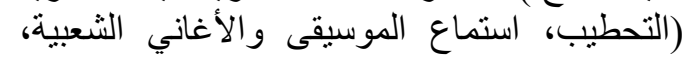
الرقصات الفلكولورية) ذـ ركن الأطفال وينقسم إلى ثلاثلاث أقسام هي:

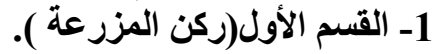

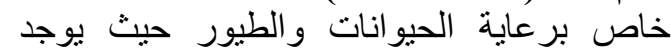
بهذالقسم حظيرة خاصة بها بها بعض الحئ الحيوانات المزرعية مثل البقر والجاموس لكي يتعرف الأطفال 
الريفية المخصصة لذلك. 8- وفي اليوم التالي يبدأ بالافطار ببعض المضاف المطولات التقليدية الشهيرة مثل الفطير المشلتت و العسل لالتطل و القشندة .

9- الخروج للتمنع بصيد البط بجزيرة دندرة بوسط الفيط

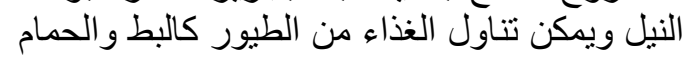

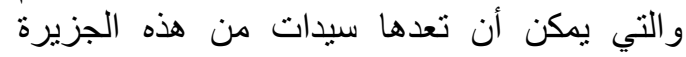

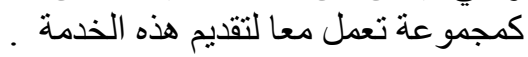

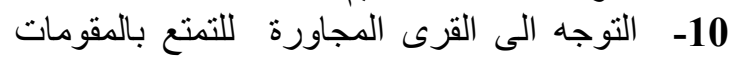

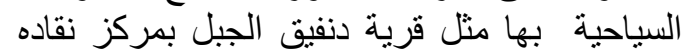

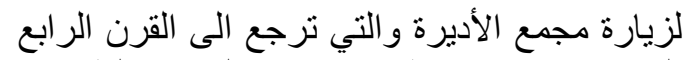

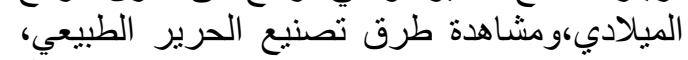

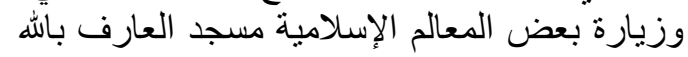
سيدي عبد الرحيم بمدينة قنا، زيارة متحف السيرة الهلالية .

11- زيارة قرية المحروسة والمعروفة بقرية البلاص

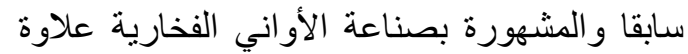

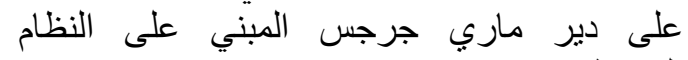
البيزنطي . 12- عمل رحلات سفاري وركوب الخيل . 13-12 رحلة العودة الى مدينة الأقصر من خلادل نهر النيل ومشاهدة تعانق الطبيعة ونهر النيلة النيل مع غروب نهرب الثمس.
في صنع هذه القلائد بأنفسه، و على غرار ذللك المشغولات الأخرى من الفخاند بأفهار و الكليم اليدوي

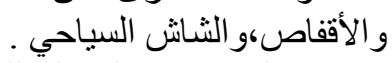

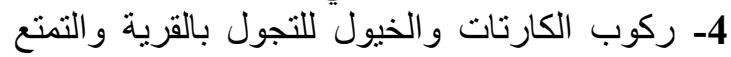

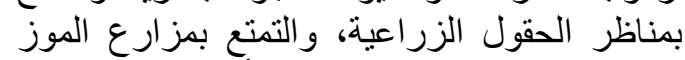

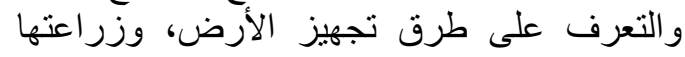

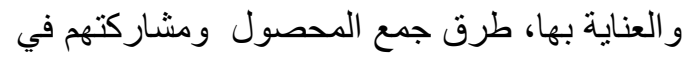
بعض هذه العمليات، وتقديم وجنات العنات خفيفة للسياح

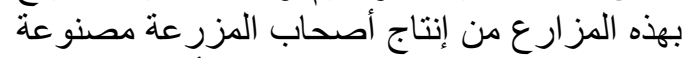

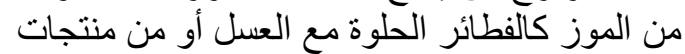

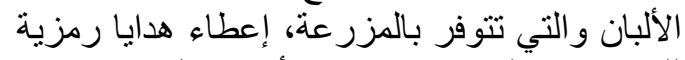

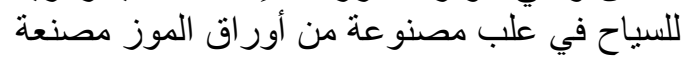
بطريقة جذابة وبسيطة.

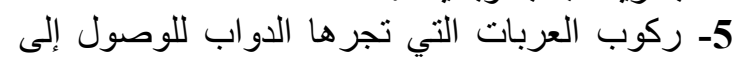

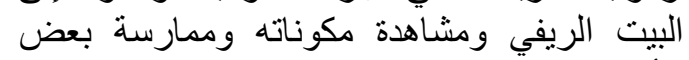

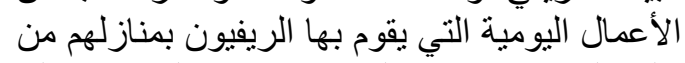

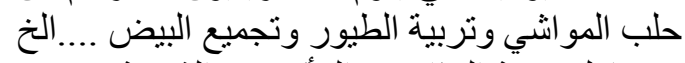
6 و وتناول وجبة الغذاء من المأكو لات الثعبية المبية .

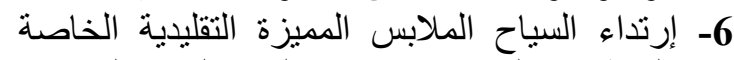
بالمنطقة، والتجمع في ساحة البراه البيت الريفي لمشاهدة

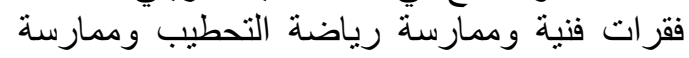

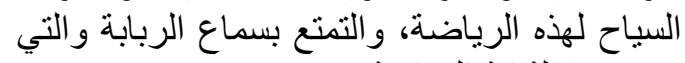
ت تتميز بها الثقافة القيناوية. 7- التمتع بقضاء ليلة بالبيت الريفي أو بأحد البيوت

نستخلص من نتائج البحث الخاصة بقرية دندرة بعض عناصر التحليل الرباعي مواطن القوة والضعف والفرص والتهديدات لتحديد اهم المقترحات:

\begin{tabular}{|c|c|}
\hline 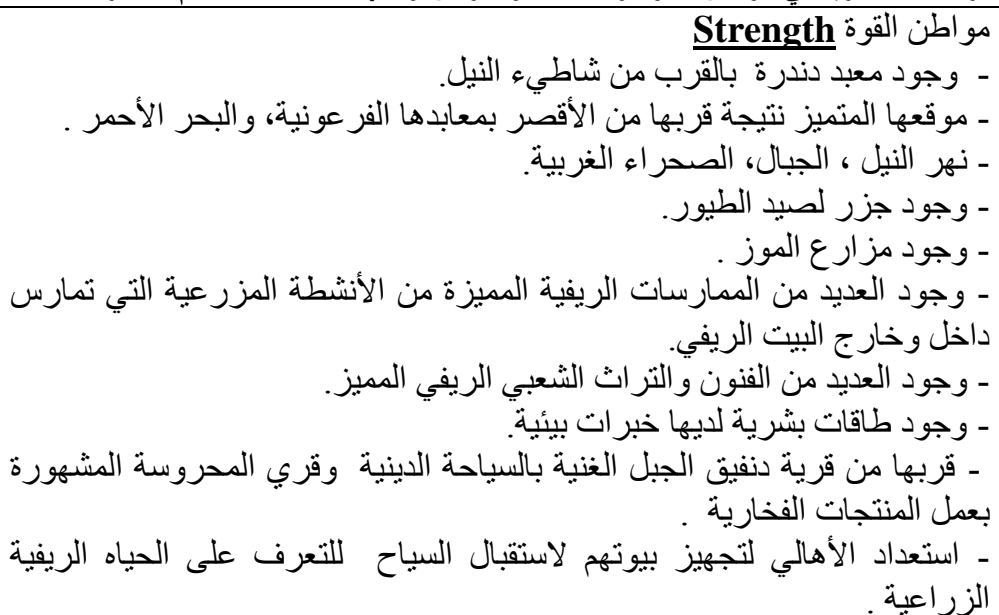 & 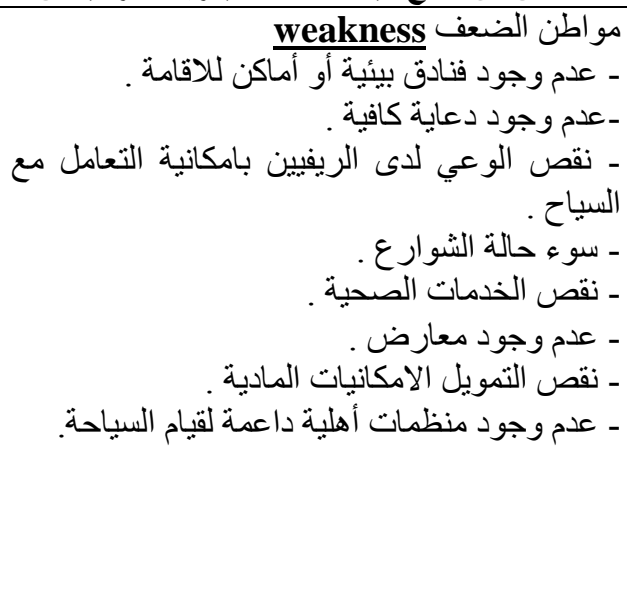 \\
\hline 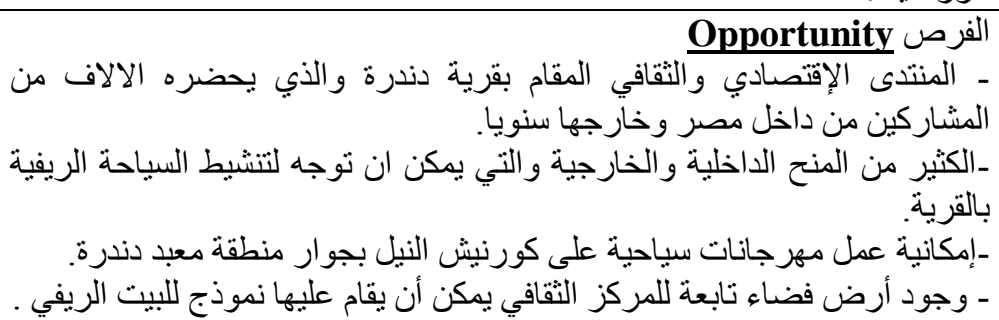 & 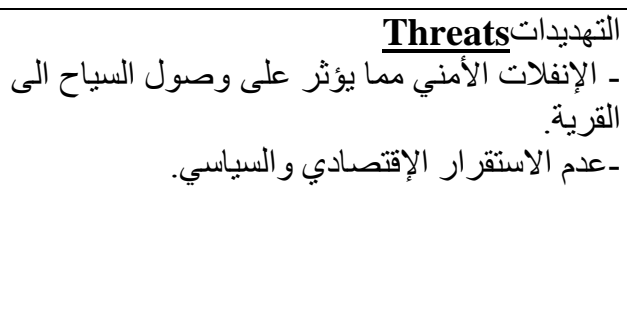 \\
\hline
\end{tabular}




$$
\begin{aligned}
& \text { 11- إنشاء فنادق بيئية ريفية بقرية دندرة. } \\
& \text { 12- زيادة التمويل الازم لتنشيط السياحة }
\end{aligned}
$$

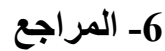

درليل محافظة قاللغة العربية السية ، مركز دندرة الثقافي،(2015)،

\section{REFERENCES}

Humaira I. (2010). Rural tourism- An overview, Agriculture and rural development. Government of Alberta,Canada pp4-7 .

Knowd I. (2001). Rural Tourism: Panacea and Paradox, Exploring the Phenomenon of Rural Tourism and Tourism's Interaction with Host Rural Communities, Studies School of Environment and Agriculture, University of Western Sydney p5: p1017.

Kostas E. S. (2002). "Rural Tourism: An opportunity for sustainable development of rural areas" pp4 .

Okech H. G. (2012). Rural Tourism as a sustainable development alternative: an analysis with special reference to Luanda, Kenya p40.

Pakurar M. and Olah J. (2008). Definion of Rural Tourism and its characteristics in the Northern Great Plain region p777.

Tuğba Kiper and Gülen Özdemir (2012). Tourism Planning in rural Areas and Organization Possibilities, Namık Kemal University, Faculty of Agriculture, Department of Landscape Architecture, Department of Agricultural Economics, Turkey p123-124.

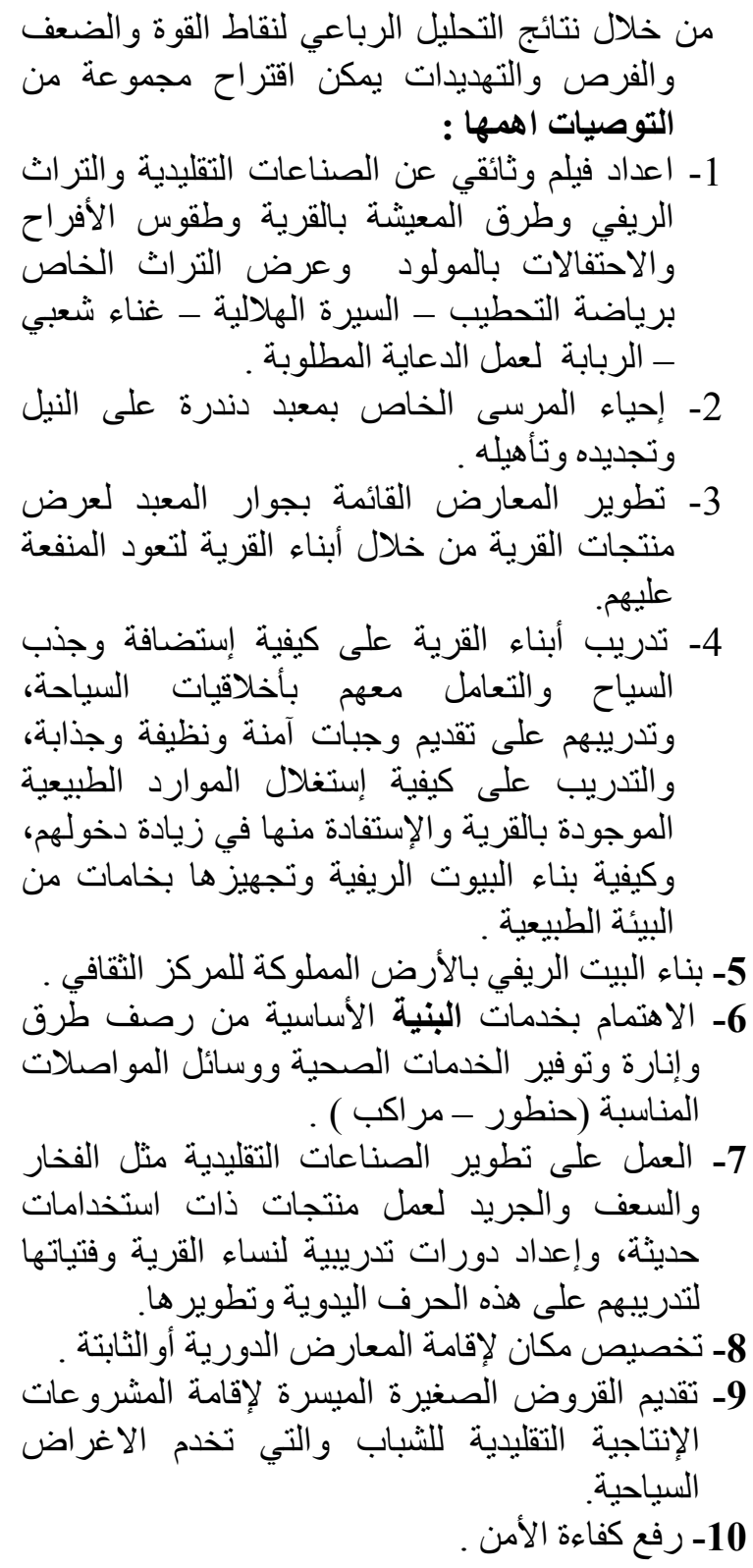

